Portland State University

PDXScholar

1989

\title{
Traditional College-Age Students' Attitudes Toward Arnold's Seven Building Blocks Decision-Making Strategy
}

Mary Ellen Wernow

Portland State University

Follow this and additional works at: https://pdxscholar.library.pdx.edu/open_access_etds Let us know how access to this document benefits you.

Recommended Citation

Wernow, Mary Ellen, "Traditional College-Age Students' Attitudes Toward Arnold's Seven Building Blocks Decision-Making Strategy" (1989). Dissertations and Theses. Paper 1337.

https://doi.org/10.15760/etd.1336

This Dissertation is brought to you for free and open access. It has been accepted for inclusion in Dissertations and Theses by an authorized administrator of PDXScholar. Please contact us if we can make this document more accessible: pdxscholar@pdx.edu. 
TRADITIONAL COLLEGE-AGE STUDENTS' ATTITUDES TOWARD ARNOLD'S SEVEN BUILDING BLOCKS

DECISION-MAKING STRATEGY

\author{
by \\ MARY ELLEN WERNOW
}

A dissertation submitted in partial fulfillment of the requirements for the degree of

DOCTOR OF EDUCATION

in

EDUCATIONAL LEADERSHIP:

POSTSECONDARY EDUCATION

Portland State University

1989 


\section{TO THE OFFICE OF GRADUATE STUDIES:}

The members of the Committee approve the dissertation of Mary Ellen Wernow presented July 17, 1989.

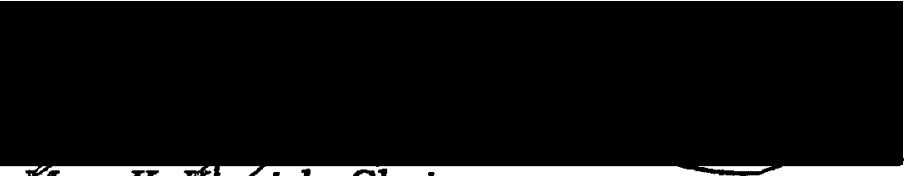

Fiary K. Khimnick, Chair

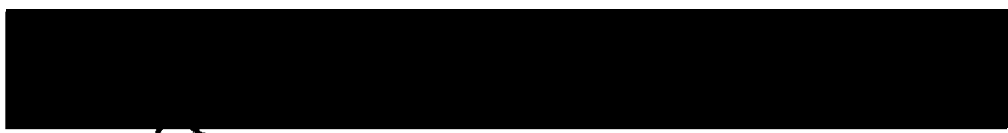

Judith Edwards Allen

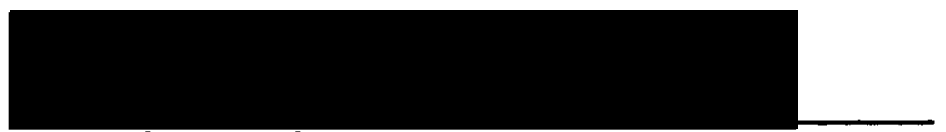

Carol A. Burden
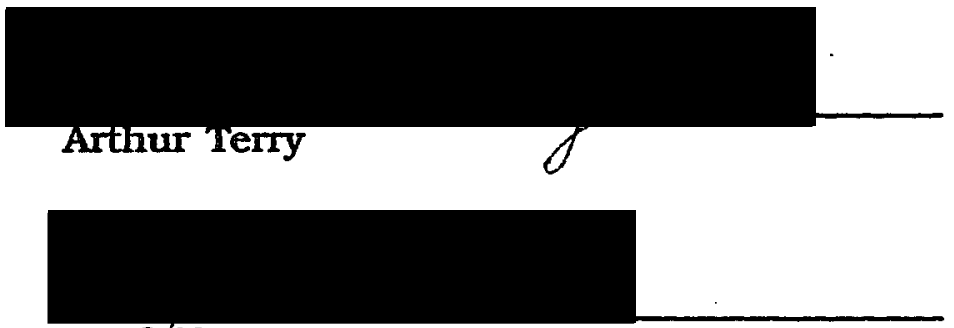

Joan/Shireman

APPROVED:

Robert B. Everhart, Dean, School of Education
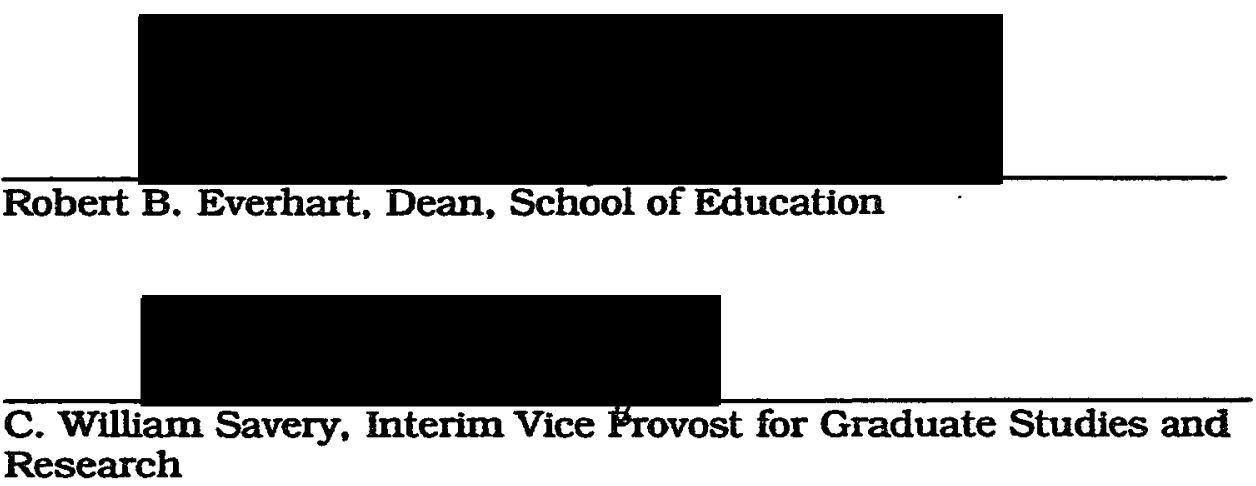
AN ABSTRACT OF THE DISSERTATION OF Mary Ellen Wernow for the Doctor of Education in Educational Leadership presented July 17, 1989.

Title: Traditional College-Age Students' Attitudes Toward Arnold's Seven Building Blocks Decision-Making Strategy.

APPROVED BY THE MEMBERS OF THE DISSERTATION COMMITTEE:

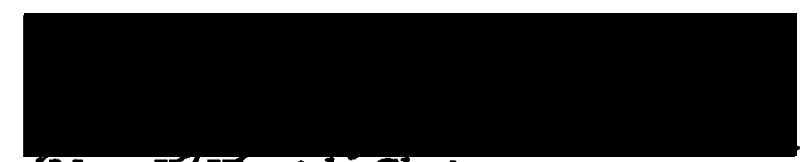

Mary $[/$ Kinnick, Chair

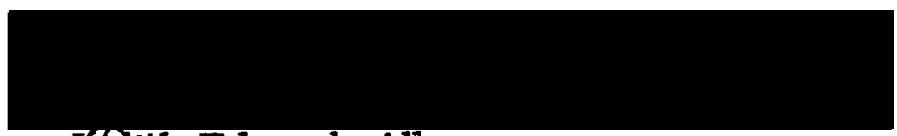

Fudith Edwards Allen

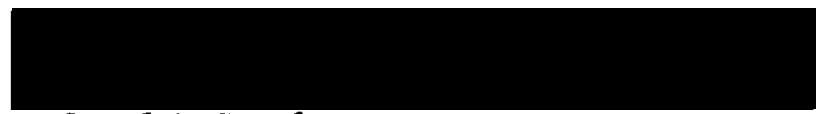

Carol A. Burden
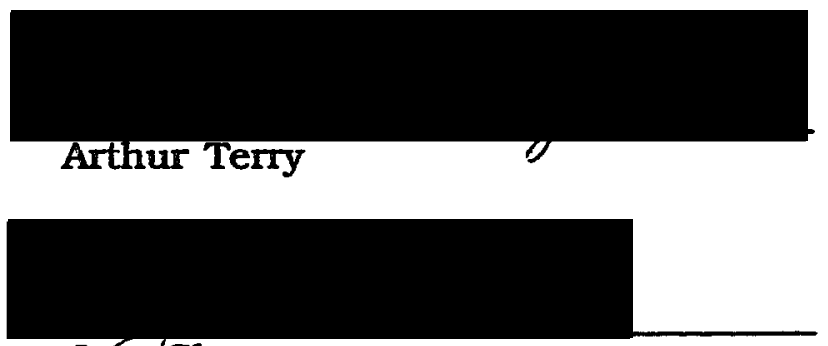

Joan/Shireman

The purpose of this study was to learn more about the attitudes of traditional college-age students toward Arnold's Seven Building Blocks decision-making strategy (John D. Arnold, 1978. The Art of Decision 
Making. New York: Amacom), to identify student characteristics which could predict those students who are most likely to respond in a positive manner to the strategy, and to determine which of the steps in the strategy students perceive as being helpful.

The sample population consisted of 62 traditional college-age students currently enrolled in four Oregon educational institutions. Data was gathered through the Decision Making Inventory [Johnson, Coscarelli, and Johnson, 1983) and two questionnaires designed for this study.

An attitude score regarding the Seven Building Blocks was constructed for each subject by adding together the scores from the two questions which specifically related to student feelings about using the strategy. This resulted in scores ranging from a low of 2 to a high of 7 .

Statistical analyses involving chi-square tests implemented by contingency tables were used to ascertain the level of association among variables. The results showed no significant difference in attitude based on the internal or external dimensions of decision-making styles, age. gender, life responsibility status, or type of decision situation. Statistically significant results $(p<.05)$ were shown for the remaining variables. Thus, for this population, characteristics associated with high attitude scores toward the Seven Building Blocks included systematic. rather than spontaneous, decision-making styles; at least two years of college education; and high or very high importance attached to being a good decision maker.

Building Block 4, "Establish Your Priorities," was overwhelmingly seen as being the most helpful step, followed by Block 3, "Set Your Criteria." Block 6, "Test the Alternatives," was third, and Block 2, "State Your Purpose," was fourth. Block 5, "Search for Solutions," and Block 7. "Troubleshoot Your Decision," tied for fifth place. Block 1. "Smoke Out the Issues," was seen as being the least helpful. 
Information obtained from this study will assist educational counselors, advisors, and teachers in understanding student attitudes toward decision making and in predicting which students are most likely to respond positively to learning and using this type of decisionmaking strategy. It is recommended that further study done in this area include investigation regarding the construction of attitude scores, as well as further corroboration of the predictor variables identified. 


\section{ACKNOWLEDGEMENTS}

I would like to thank Dr. Mary Kinnick for her insight and guidance in this project, and for her excellent prodding which encouraged me to complete this work.

To Dr. Judith Edwards Allen, Dr. Carol Burden, Dr. Arthur Terry, and Dr. Joan Shireman, I express my gratitude for their helpfulness and cooperation as they served on my committee.

I am thankful for all the students who participated in this study, and who told me how they honestly felt about the decision-making strategy which I investigated.

A special note of thanks goes to my friend, Pat Cunningham, for his advice and assistance with the statistical analyses.

I am grateful to my husband, Jerome, for his unswerving belief in my ability to undertake and complete this project, and for his help which made it possible for me to do so. I appreciate the patience of my son, Josiah, in putting up with my endless hours at the computer, and the warm and loving support of my parents, Don and Evelyn Pierce. I am also thankful for the excellent editing provided by my sister, Joy Kristoffersen.

Finally, I acknowledge that it is God who provided me with this opportunity to further my education and who gave me the strength to accomplish the tasks involved.

"Commit to the LORD whatever you do, and your plans will succeed" (Proverbs 16:3). 
TABLE OF CONTENTS

PAGE

ACKNOWLEDGEMENTS .................. iii

LIST OF TABLES ...................... . viii

LIST OF FIGURES . . . . . . . . . . . . . . . . $\mathrm{x}$

CHAPTER

I INTRODUCTION .................. 1

Statement of the Problem ........... 4

Purpose of the Study . . . . . . . . 5

Theoretical Framework for the Study . . . . . 6

Research Questions ........... 7

Limitations of the Study . . . . . . . 8

Assumptions ................... 9

Definitions. ............. 10

II REVIEW OF RELATED LITERATURE . . . . . . . . . 11

Late Adolescent and Youth Development . . . 12

Developmental Tasks

Cognitive Development

Learning Style Theory . . . . . . . . 13

A Comparative Study of Johnson's Theory and

Related Theories .......... 15

Formal Decision Theory . . . . . . . . . 15

Central Concepts of Formal Decision Theory

Decision Analysis 
Basic Principles of Decision Making . . . . . 18

Defining Decision Making

Decision Blockers

Precipitation of Decision Making

The Decision-Making Process . . . . . . .

Wheeler and Janis' Five-Stage DecisionMaking Strategy

Arnold's Seven Building Blocks

Career Decision-Making Studies . . . . . . .

A Career Choice Class

A Decision-Making Course

Summary. . . . . . . . . . . . 28

III RESEARCH PROCEDURES ........... 29

Rationale for Using Arnold's Seven Building

Blocks ............ 29

Research Questions and Their Corresponding

Hypotheses............ 31

Research Methodology . . . . . . . . 34

Subjects............... 34

Instruments ............ 37

The Decision Making Inventory

The Decision Making Questionnaire

The Response to Arnold's Seven Building Blocks Questionnaire

The Seven Building Blocks Handout

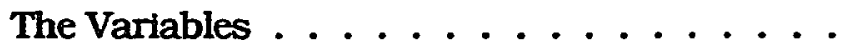

The Independent Variables

The Dependent Variable.

Field Procedures . . . . . . . . . . . 42

Analysis of Data . . . . . . . . . . 43 


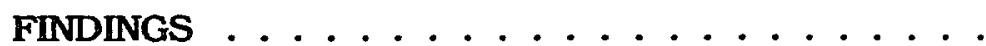

The Association Between Attitude Toward the Seven Building Blocks and Decision-

Making Style . . . . . . . . . . .

The Spontaneous and Systematic Dimensions

The Internal and External Dimensions

Summary

The Association Between Attitude Toward the Seven Building Blocks and Other

Variables ............ 52

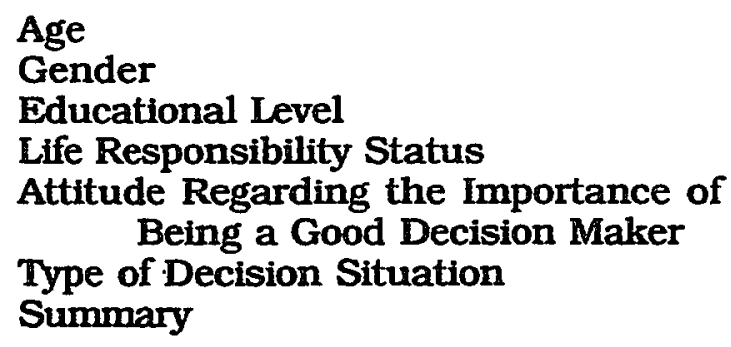

Student Perception of the Helpfulness of the Various Steps in the Seven Building

Blocks

Summary

Other Interesting Findings . . . . . . . 70

Educational Level and Spontaneous and Systematic Dimensions

Decision-Making Style and Gender

Summary

V CONCLUSIONS AND RECOMMENDATIONS . . . . 75

Summary .............. 75

Conclusions of the Review of Literature Research Questions Investigated Procedures Followed

Implications ............ 79

Contribution to the Field of Education Recommendations for Further Study

Applications. . . . . . . . . . . 84 
Conclusions .............. 85

Selected Findings

Conclusions Related to the Research Questions

Recommendations ........... 89

Recommendations for the

Implementation of the Findings

Recommendations for Further Research

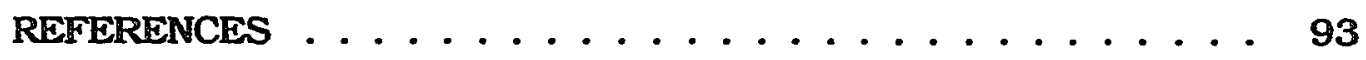

APPENDICES ...................... 100

A THE DECISION MAKING INVENTORY . . . . . 100

B THE DECISION MAKING QUESTIONNAIRE . . . . 102

C THE RESPONSE TO ARNOLD'S SEVEN BUILDING

BLOCKS QUESTIONNAIRE . . . . . . . 106

D THE SEVEN BUILDING BLOCKS HANDOUT . . . . 111

E LECTURE NOTES FOR TEACHING THE SEVEN

BULLING BLOCKS . . . . . . . . . . . . 122

F TRANSPARENCIES FOR TEACHING THE SEVEN

BULDING BLOCKS . . . . . . . . . . 130

G EXPLANATION OF DECISION-MAKING STYLE DIMENSIONS ............ 138

H STUDENT RESPONSES TO THE SEVEN BUILDING BLOCKS ............... 141 


\section{LIST OF TABLES}

TABLE

PAGE

I Demographic Profile of the Subjects . . . . . . 36

II Decision-Making Profile of the Subjects . . . . . 37

III Association of Attitude Scores with Spontaneous and Systematic Decision-Making Dimensions . 49

IV Association of Attitude Scores with Internal and External Decision-Making Dimensions . . . . 50

V Association of Attitude Scores with Age Classification ............. 53

VI Association of Attitude Scores with Gender . . . . 54

VII Association of Attitude Scores with Educational Level (High School and College). . . . . . . 55

VIII Association of Attitude Scores with Educational Level ( 0 and 1 or More Years). . . . . . . 56

IX Association of Attitude Scores with Educational Level Classification (0-1 Year and 2 or More Years) ............... 57

X Association of Attitude Scores with Living Situation 60

XI Association of Attitude Scores with Work Situation . 61

XII Association of Attitude Scores with Importance Attached to Being a Good Decision Maker . . . 62

XIII Percentage of the Possible Vote for Each of the Seven Building Blocks .......... 68

XIV Order of Perceived Helpfulness of the Seven Building Blocks . . . . . . . . . . . 68

XV Association of Educational Level with Spontaneous and Systematic Decision-Making Dimensions . 71 
XVI Association of Spontaneous and Systematic

Decision-Making Dimensions with Gender . . 72

XVII Association of Internal and External DecisionMaking Dimensions with Gender . . . . . 72 


\section{LIST OF FIGURES}

FIGURE

PAGE

1. Alternative Rating Chart .......... 25 


\section{CHAPTER I}

\section{INTRODUCTION}

Indecision is a problem which strikes most, if not all, college students at some point in their educational career. It is a problem which is exacerbated by the fast-paced society in which we live. Modern medicine has brought to the foreground a host of ethical dilemmas requiring the making of difficult decisions. The abundance of information available has resulted in increased awareness of political, religious, economic, environmental, and social problems which require decisions. The broad spectrum of occupations currently open to young people is exciting, but can also be overwhelming to a college-age decision maker.

While indecision is certainly no crime, it does pose a challenge which must be addressed by the educational institution. Many colleges and universities have sought to address this challenge through the establishment of student services programs. These programs seek to accomplish one or more of the following purposes: (1) provide essential institutional services; (2) teach life management skills, such as decision making; and (3) provide an arena in which students can integrate the knowledge which they are gaining in a useful manner (Barr and Keating, 1985). 
The questions which student services personnel should be asking regarding the future of their programs include the following:

"What repertoire of skills and competencies constitute the educated person?" and "How can we intentionally design environments that will foster the educational process?" (Hurst and Jacobson, 1985, p. 121).

Gordon (1984) includes self-awareness and understanding of the world of work, interpersonal skills, employment skills, coping skills for the future, goal-setting skills, and decision-making skills in his list of capabilities necessary for a student in the process of setting educational and career goals. These are skills which are needed by educated persons.

Group counseling, individual counseling, and courses in career development are all means which are currently being utilized by educational institutions to deal with the problem of facilitating student acquisition of relevant skills. These are environments which have been designed to foster the process of education. Yet more remains to be done.

Shipton and Steltenpohl (1981), in an article on educational advising and career planning, conclude that modern American colleges need to have a carefully organized plan for providing students with opportunities to undertake career and educational planning. They posit that educational and vocational advising should be seen as part of life planning. Advising should be organized to facilitate student decision making and planning, should be based on the steps in the decisionmaking process, should include self-directed information gathering about self and the external world, and should involve cooperation between faculty and student services staff. The goal of every adviser or counselor, regardless of formal position in the institution, should be to help students become self-directed by guiding them in applying the planning process in their educational and career decisions. In this way students will be able to assume greater responsibility for their own education and life planning. 
American education is gaining awareness at the national level of the nced to prepare students to think on their own. In light of the rapid rate of change in our society, success in life and in school will depend on an ability to define problems and issues, to make effective decisions, and to seek creative solutions.

Traditionally, college has been seen as a place where one acquires academic skills, chooses and prepares for a career, and develops personal values. As a matter of course, our schools have required that students learn, analyze, solve problems, and make decisions. Yet these same schools have failed to teach students how to perform these vital educational skills. The underlying assumption has been that students already know how to think, but recent research has shown that this is not the case. Psychological testing of first year college students has shown that only $25 \%$ of them scored at the Formal Level of thought on Piagetian tests assessing the thinking skills necessary for logical thought (Halpern, 1987).

Teachers at high school and college levels have long been aware of the lack of basic thinking skills among their students, and the impact which this has upon education. Berger, Pezdek, and Banks (1987) posit that the failure of students to develop basic problem solving and critical thinking skills has become a major obstacle in education, and has recently become the focus of national attention. Presseisen (1986) proposes that we consider thinking as the major goal at all levels of education, an assessment which is echoed by Meyers (1987). At the national level, the improvement of critical thinking skills has now become a recognized goal (Berger, Pezdek, and Banks, 1987).

According to Halpern (1987, p. 75), critical thinking refers to "systematic, goal-directed thinking that includes evaluation of the assumptions, processes, and outcome in making a decision, solving a problem, or formulating inferences from information given." This definition shows that critical thinking is an integral part of decision making. At the same time, critical thinking can be seen as the umbrella 
term for the kind of thought processes used for a variety of activities. one of which is making decisions.

There is growing interest in the United States and in other countries concerning the development of courses aimed at helping students improve their critical thinking skills (Halpern, 1987). Some researchers, such as Meyers (1987), feel that critical thinking must be taught within the framework of specific disciplines and should be integrated into the teaching structure of each discipline. Most educators, however, also see the value and efficacy of separate thinking courses, including the teaching of metacognitive processes, formal operational reasoning models, the skills of logic and inquiry, and decision-making models (Nummedal, 1987).

\section{STATEMENT OF THE PROBLEM}

Teaching effective decision-making skills is one objective of the overall goal of teaching critical thinking skills. Since decision making is a necessary ingredient in student advising and counseling, it is a skill which can logically be taught within the framework of student services programs. This is not to say that good decision-making skills should not be taught within academic courses, but rather that they must also be addressed by student services personnel and programs.

The large number of students being served by institutions of higher education means that educational advising and counseling usually consist of brief encounters between students and their faculty advisers or counselors. Most schools cannot afford to greatly increase their personnel resources in order to expand their services, and therefore need to make the most of the resources they do have. A repertoire of useful tools and strategies to aid in providing services and a means of appropriately matching these tools to individual students could enable existing personnel to serve these students more effectively. 
Is there a way of determining which tools will work with various students? Is there a way to help counselors predict who will benefit from a particular strategy? What strategies exist which are appropriate for traditional college-age students? How can these strategies be used effectively?

This study looked at one decision-making strategy and sought to ascertain its appeal to traditional college-age students. Associational patterns were sought between student attitude toward this strategy and a variety of student characteristics, including decision-making style, age, gender, educational level, and life-related data.

\section{PURPOSE OF THE STUDY}

The purpose of this study was to learn more about the attitudes of traditional college-age students toward Arnold's (1978) Seven Building Blocks decision-making strategy, and to seek a pattern which might indicate that students who find the strategy appealing tend to have a particular style or styles of decision making and/or a particular combination of personal characteristics.

It is hoped that information obtained from this study will assist educational counselors, advisors, and teachers in understanding student attitudes toward decision making in general and toward the Seven Building Blocks specifically. It is further hoped that this study will aid counselors and advisers in predicting which students are most likely to respond positively to learning and using this kind of decision-making strategy.

Information collected included student decision-making styles as determined by the Decision Making Inventory (Johnson, Coscarelli, and Johnson, 1983), age, gender, educational level, level of independence and family responsibility, work situation, attitude regarding decision 
making. type of decision situation dealt with using Amold's strategy, and student attitude regarding the strategy.

Data were gathered through the Decision Making Inventory, a front end decision-making questionnaire, and a response questionnaire designed to obtain feedback regarding students' attitudes toward the Seven Building Blocks. The sample population consisted of 62 traditional college-age students currently enrolled in Oregon educational institutions.

\section{THEORETICAL FRAMEWORK FOR THE STUDY}

College students are involved in making educational, career, and life decisions. According to Gordon, Coscarelli, and Sears (1986), their learning and decision-making styles are influenced by the manner in which they blend attitudes, perceptions, judgment, and other personality characteristics in their individual approaches to decisions. Since the processes students use to learn and make decisions are an integral part of student-teacher and student-counselor interactions, counselors and teachers need to understand these processes.

There are many individual differences in the way people handle information (Coscarelli, 1983). While the differences are viewed variously as cognitive styles, learning styles, or decision-making styles, there is a sense that people do indeed have preferred ways of gathering. organizing, and processing information.

As a result of a year-long study of clients in a counseling center, Johnson developed the framework for a theory of decision making which "would aid practicing counselors in understanding their clients' unique decision making (sic) styles and would aid researchers in their conduct of decision making (sic) research" (Johnson, 1978, p. 531). He states that people have distinct styles of collecting and processing data, 
and that these styles have value in predicting choices. He further posits that research regarding educational and occupational choices shows a lack of correlation between demographic or cultural factors and prediction of choice.

Johnson's theory divides decision-making behavior into two processes: information gathering and information analyzing. Each of these processes contains two basic dimensions. A person may gather information in a spontaneous or a systematic manner, and may process that information using either an external or an internal process. Spontaneous individuals tend to react holistically to events, commit themselves rather quickly to an alternative, change commitments easily, and be flexible in moving from one goal to another. Systematic people, on the other hand, react independently to the component parts of an experience, are cautious in making psychological commitments to alternatives, are cautious about changing commitments, and are methodical in their goal orientation. In analyzing data. external processors tend to think as they talk while internal processors prefer to think before they talk.

In his investigation. Johnson (1978) found that the data gathering and analyzing styles were independent. Therefore, he proposed that there are four distinct categories of decision-making styles: spontaneous external, spontaneous internal, systematic external, and systematic internal. These styles can be identified using the Decision Making Inventory developed by Johnson, Coscarelli, and Johnson (1983).

\section{RESEARCH gUESTIONS}

This study addressed the following questions:

1. Do the Seven Building Blocks appeal equally to traditional collegeage students with varying decision-making styles? If not, is there 
a pattern which might indicate that students with a particular decision- making style find this strategy more or less appealing?

2. Is there an association between student attitude toward the Seven Building Blocks and age, gender, educational level, life responsibility status, attitude regarding decision making, and/or type of decision made using the strategy?

3. Which of the steps in the Seven Building Blocks do students perceive to be helpful?

\section{LIMITATIONS OF THE STUDY}

1. This study was limited to traditional college-age students in two geographic areas of Oregon: metropolitan Portland and the Albany-Corvallis area. Data collected from students in the classes and seminars who were younger or older than the traditional college age (ages 16 to 23) were excluded from the study. Transferability of data to other geographic areas or other ages is not known.

2. This study basically included students from traditional Oregon cultural backgrounds. Transferability of data to students of other cultural backgrounds is not known.

3. Student exposure to Amold's Seven Building Blocks decisionmaking strategy was limited to brief presentations made by the researcher and information contained in a 10-page worksheet which guided students in making a decision using the strategy. Students spent a total of approximately two hours learning about and using the strategy through a combination of lecture and time spent working through a decision using the strategy. 
4. Students' decision-making styles were determined by the Decision Making Inventory (Johnson, Coscarelli, and Johnson, 1983). No other inventory of learning style, decision-making style, or personality type was used.

5. The researcher's decision-making style, as identified by the Decision Making Inventory, is systematic internal. This style may well have influenced the choice of the Seven Building Blocks as an appropriate strategy to use in teaching students effective decision-making skills.

\section{ASSUMPTIONS}

1. It is assumed that John Arnold's Seven Building Blocks is an appropriate decision-making tool to use with at least a percentage of the traditional college-age population.

2. It is assumed that the researcher's presentation of Arnold's Seven Building Blocks decision-making strategy represented the strategy in an accurate and comprehensible manner.

3. It is assumed that the sample population was a representative sample of traditional college age students, at least in the geographical area and culture studied.

4. It is assumed that decision making is a rational process, but one which also encompasses emotions.

5. It is assumed that the examination of alternatives in seeking a solution is appropriate for making decisions in a democratic society. 


\section{DEFINITIONS}

1. Traditional college-age: Students who are at least 16 and not more than 23 years of age.

2. Critical thinking: "Systematic, goal-directed thinking that includes evaluation of the assumptions, processes, and outcome in making a decision, solving a problem, or formulating inferences from information given" (Halpern, 1987, p. 75).

3. Decision making: The process of making reasoned choices which are based on judgments consistent with the decision maker's values, as well as on accurate, relevant information.

4. Decision-making style: The distinct, characteristics methods an individual uses for collecting and processing data.

5. Cognitive style: The information processing habits characteristic of a person's normal manner of perceiving, thinking, remembering, and problem solving.

6. Learning style: The composite of characteristic cognitive, affective, and physiological components which serve as relatively stable indicators of how a learner perceives, interacts with, and responds to the learning environment. 


\section{CHAPTER II}

\section{REVIEW OF RELATED LITERATURE}

American educational institutions have long recognized the need to provide counseling and advising for their students. Much progress has been made in developing student services programs. Individual and group counseling, vocational advising, and career information and planning resources are a vital part of today's colleges and universities. Yet there is little research available regarding effective methods and strategies currently being used to help students make the important decisions necessary to benefit from these student services programs.

At the national level, the teaching of critical thinking skills such as logic, reasoning, recall, analysis, comparison, inference, evaluation, and decision-making skills has become recognized as being a major goal in American education. This should result in more courses and programs designed to teach these vital skills, as well as more research regarding the effectiveness of these programs.

The literature reviewed for this investigation is categorized into eight areas:

1. Late adolescent and youth development:

2. Learning style theory;

3. A comparative study of Johnson's decision-making theory and related theorics:

4. Formal decision theory: 
5. Basic principles of decision making;

6. The decision-making process;

7. Decision-making strategies; and

8. Career decision-making course studies.

\section{LATE ADOLESCENT AND YOUTH DEVELOPMENT}

\section{Developmental Tasks}

Chickering and Havighurst (1981) designate ages 16 to 23 as late adolescence and youth. This is the age group of traditional college-age young people. According to Chickering and Havighurst, the major developmental tasks which must be accomplished by this group are the following: achieving emotional independence, preparing for marriage and family life, choosing and preparing for a career, and developing an ethical system. Probably the most challenging of these, according to Chickering and Havighurst, is choosing and preparing for a career. The choice of a career is the organizing center for the lives of most of the men and women of this age group. It is an essential part of gaining emotional independence and is a basis for making decisions regarding marriage and family.

Shipton and Steltenpohl (1981) state that the majority of college students do not set life goals thoughtfully and do not have welldeveloped strategies for attaining their goals; only a limited number of students begin college with clearly defined educational goals and purposes. They posit that traditional college-age students need opportinities to develop useful skills and explore alternatives before making commitments. They need help in clarifying their life, career, and educational goals. Educational counseling and advising must focus on helping students take responsibility for their own lives and decisions 
so they can move toward autonomy. Integral to this process of development is the acquisition of skill in decision making. Traditional college-age students can anticipate a recurring need for decisionmaking skills as they move through the stages of adult development.

\section{Cognitive Development}

Classic cognitive developmental theory (Inhelder and Piaget. 1958) claims that adolescents past the age of 15 have reached the formal operational level and are capable of adult thinking. They are no longer dependent on concrete referents, but are able to distinguish reality from possibility, to think reflectively and abstractly. While this may be true of many 16- to 23-year olds, research has shown that it is not true of adolescent thinking in general. Nummedal (1987) states that less than half of American university students are capable of using formal reasoning processes with confidence and reliability. She further posits that three-fourths of students will not develop good reasoning skills without the explicit teaching of these critical thinking skills.

If critical thinking skills are to be taught. they must be defined and measured. Stiggins, Rubel, and Quellmalz (1988) include recall, analysis, comparison, inference, and evaluation in their summary of thinking skills. They recommend that these skills be measured through the use of oral questions during instruction, objective paper-and-pencil tests, and performance assessment based on teacher observation and subjective judgment.

\section{LEARNING STYLE THEORY}

Smith (1982) states that people vary in the way they characteristically process information, in their attitudes toward learning, and in their preferences for teaching methods, learning 
environments, and class structure. These differences have been termed learning styles, and encompass three major components: cognitive, affective, and environmental factors.

Cognitively, people vary in their perception of their environment. Some people are more analytical, or field-independent, while others perceive things in a global or field-dependent manner. In conceptualizing and categorizing information, some people are more relational and others more analytical and descriptive. People differ in the way they process information, with some individuals being more reflective and others more impulsive. There are three different sensory modalities: physical, spatial, and verbal. People differ in their preferences for one or another of these ways of thinking.

Affective factors in learning style include learners' attitudes toward structure and authority in the learning situation, their expectations and motivation regarding learning tasks, and the degree of interest which they have for the subject matter.

Environmental factors include preference variations in temperature, amount of light, type of desks and chairs, absence or presence of sound, time of day, and personal or formal learning environment (Smith, 1982).

Counselors and teachers need to be aware of differing learning styles in order to be sensitive to individual learners. While most educators are not in a position to provide separate classes for the various learning styles, they can use knowledge of learning styles to help them adapt instruction to the variety of learners with whom they interact. 


\section{A COMPARATIVE STUDY OF JOHNSON'S THEORY AND RELATED THEORIES}

Gordon, Coscarelli, and Sears (1986) conducted a study of university students in which they investigated common elements between Johnson's (1978) theory of decision-making styles and other decision-making and learning theories. This study looked at the relationship of general decision-making style, as measured by the Decision Making Inventory (DMI), and career decision-making style, as measured by the Assessment of Career Decision Making (ACDM-S): the relationship of general decision-making style and learning style, as measured by the Learning Style Inventory (LSI); and the relationship between general decision-making style and the way students process information, as measured by the Myers-Briggs Type Indicator (MBTI).

This study showed fewer similarities between the various dimensions studied than might be expected. The differences were thought to be caused by theoretical differences between the dimensions. While there was some overlapping between the DMI and the other inventories, it was concluded that the greater number of differences suggested that the constructs measured by the DMI are likely distinct styles.

\section{FORMAL DECISION THEORY}

Horan (1979) presents a concise overview of decision making. looking at the broad spectrum of fields which deal with the issues of making decisions, and focusing on applications relevant to counseling. On page 2 of his book, Counseling for Effective Decision Making, he sets forth a case for drawing from research and theory in decision making which comes from fields such as statistics, economics. business. politics, psychology, and counseling. 
A number of prominent individuals in the counseling profession (for example. Gelatt, 1962; Herr, 1970; Tyler, 1969) have suggested that the primary responsibility of counselors is rendering assistance to clients with decisionmaking concerns. Unfortunately, there has not been strong consensus in the counseling profession as to how this service ought to be provided. All major counseling theories either ignore the topic of decision making or address it imperfectly. Morecver, the counseling literature has paid scant attention to theory construction and research on decision making that has occurred in other fields. Much of this work has strong implications for the practice of decision-making counseling.

\section{Central Concepts of Formal Decision Theory}

Horan (1979) states that the basic concepts of decision theory are value and probability. Value refers to the desirability of an object or an outcome. In individual decision making, values are necessarily subjective. Measuring subjective value, or utility, is difficult, but the use of simple self-report scales, such as rating items on a scale from 1 to 10 , are recommended in situations involving personal choices (Edwards and Fishburn, personal communication cited in Horan, 1979).

Probability refers to the likelihood that a given event will occur. The usual formula used in defining probability is as follows:

$$
\text { Probability of an outcome }=\frac{\text { Frequency of that outcome }}{\text { Total number of cases }}
$$

Probabilities (symbolized by $p$ ) are written as fractions, with 0 indicating no possibility of an event occurring and 1.00 indicating certainty that the event will indeed occur. An event which is expected to happen half of the time would be said to have a $p$ of .50 (Anderson, 1980).

There are four possible permutations of objective and subjective value and probability, but most current formal decision theory occurs within the subjectively expected utility maximization model (SEU). 
which asserts that people make decisions on the basis of utility and subjective probability.

Wheeler and Janis (1980) state that there are two central ideas of formal decision theory which should be remembered when making vital decisions. The first idea stresses the importance of making the best possible estimates of the probability of the occurrence of each expected outcome in order to make a good decision. The second central idea is that a good decision must take into account the expected utility value of each positive or negative aspect, relative to the decision maker's value system.

\section{Decision Analysis}

Keeney (1982) presents a helpful overview of decision analysis, which is a term that refers to the formal use of common sense for solving complex decision problems. According to Keeney, a technical definition of decision analysis is "a philosophy, articulated by a set of logical axioms, and a methodology and collection of systematic

procedures, based upon those axioms, for responsibly analyzing the complexities inherent in decision problems" (p. 806). Decision analysis focuses on the following five areas: (1) a perceived need to accomplish objectives; (2) a variety of alternatives, one of which needs to be selected: (3) different consequences associated with each of the alternatives; (4) the uncertainty concerning the consequences of each alternative; and (5) unequal valuing of the various consequences.

In evaluating the various consequences of alternatives, decision analysts structure the problem, assess the possible impacts of each alternative, determine the preferences or values of the decision makers. then evaluate and compare alternatives. Problem objectives are used to stimulate creativity in generating alternatives. When objectives are clear, desirable consequences can be described. One can then ask what type of alternative might result in these consequences. By looking first 
at the end results desired, the decision problem is actually broadened, as are the possible alternatives. In this situation,

A critical change is the introduction of dynamic alternatives rather than reliance on static alternatives alone. The difference is that a dynamic alternative is designed to be adapted over time based on external circumstances and new information (Keeney, 1982, p. 809).

Two further issues in decision analysis are value tradeoffs and risk attitudes. Value tradeoffs refer to what one is willing to give up in regard to one objective in order to achieve a measure of improvement in another objective. Risk attitudes answer the question, "Are the potential benefits of having things go right worth the risks if things go wrong?" (Keeney, 1982, p. 813). Both of these issues need to be considered in evaluating alternatives.

\section{BASIC PRINCIPLES OF DECISION MAKING}

\section{Defining Decision Making}

In looking at the basics of decision making, it would be well to begin with how several leading theorists define what decision making is. Heppner and Krieshok (1983, p. 241) see decision making as referring to "the specific activities involved in deciding among alternatives (e.g., assessing probabilities and weighing consequences)." Another definition is offered by Cassidy and Kurfman (1977, p. 1).

Decision making can be defined as the making of reasoned choices from among several alternatives. Reasoned choices are choices based on judgments which are consistent with the decision-maker's values. They are also choices based on relevant, sound information.

Rubin (1985, p. 11) defines a decision as "a free, unconditional. total and personal commitment to a choice or an option, or a group of them." 
Each of these theorists incorporates the concept of choice and the idea of a variety of possible alternatives. Heppner and Krieshok speak of assessing and weighing, while Cassidy and Kurfman use the term "reasoned choices." Cassidy and Kurfman bring in the concepts of the decision-maker's values and the necessity of good information. Rubin adds the idea of personal commitment to the choice as part of the decision.

\section{Decision Blockers}

According to Rubin (1985), there are many things which can block decision making. Some of these are losing touch with one's feelings: resignation, or the avoidance of anxiety from potential conflict: a lack of well-thought-out personal priorities; a lack of confidence or poor self-esteem; hopelessness, depression, or severe anxiety; an unrealistic image of one's self; self-erasing, inappropriate dependency on others, or an obsessive need to be liked; an obsessive quest for applause and mastery; perfectionism; and a sustaining belief that something better will come along, otherwise seen as wishful thinking.

In order to be involved in appropriate and positive decision making, a person needs to be free from those attitudes and behaviors which block decision making, secure in his or her self-identity, and free to make a dedicated commitment to a choice.

Osipow (1983) posits that an interdependence exists between one's self-view and the choices one makes, as well as between one's personality variables and current environmental conditions. In order to feel ownership in a decision and commitment to it, one's feelings and values must be taken into account. Effective decision making will be based upon the value system of the decision maker, rather than upon what a decision facilitator sees to be "the obvious, rational thing to do." Furthermore, the decision which is most likely to be carried out will be one to which the decision maker is committed. 


\section{Precipitation of Decision Making}

According to Osipow (1983), decision making does not just happen. People do not usually make decisions unless they are required to do so, either by an educational system, a life situation, or by the feeling that a previous decision no longer fits them or their situation. He suggests this can be caused by changes in the individual or in the environment which make earlier decisions no longer congruent with the individual's characteristics or values.

Zaccaria (1970) asserts that most American young people engage in three fundamental decision-making processes which impact their entire lives. These processes are the development of a philosophy of life involving a set of life values, the choice of a career, and the choice of a life partner. At a time when so many vital life choices are in the process of being made, good decision-making skills should be utilized. Yet many, if not most, young people engage in a "muddling through" process of deciding on important life issues. This process is described by Healy (1982) as being developmental, and begins with exploration. leads to crystallization of a chosen direction, and continues with affirmation of a choice or objective. Clarification follows, then implementation of trial plans, a reformulation of one's identity, and, eventually, the integration of the individual's new personal characteristics. While many satisfactory decisions are made using such a process, it is a rather frustrating method and one which does not engender a great deal of confidence on the part of the decision maker.

With so much at stake, today's college students need to be exposed to effective decision-making techniques. They need to be given the opportunity to develop the good decision-making skills they will need throughout their adult lives. 


\section{THE DECISION-MAKHNG PROCESS}

While there is no real consensus as to exactly how many stages of decision making there are, it is generally agreed that distinct stages do exist. Most decision-making models include a three to eight step decision process. Zakay and Barak (1984) include seven main stages. These are (1) defining the problem; (2) generating alternatives; (3) gathering information; (4) processing information: (5) making plans; (6) selecting goals; and (7) implementing those plans. Others may add. delete, or restate some stages, but most decision-making models follow this basic pattern (see Arnold, 1978; Gelatt, 1962; Horan, 1979: Janis. 1982a; Janis and Mann, 1982; McMinn and Libby, 1980; Patterson and Eisenberg, 1983; Rubin, 1985; and Wheeler and Janis, 1980).

One of the best-known models of decision making is that of Simon (1977), who delineates a three-stage process of intelligence, design, and choice. In the first stage, the problem is identified and information is acquired which aids in defining the problem. In the design stage, alternative solutions are generated and developed. In the final stage, that of choice, the various solutions are evaluated, chosen, and then implemented.

The decision-making process is further described by Shipton and Steltenpohl (1981) as a strategy for processing three systems of data: (1) an information system, (2) a values system, and (3) a prediction system. The steps in this process include (1) defining the task, (2) gathering information, (3) establishing a values hierarchy, (4) making a choice, and (5) taking action.

Two well-defined approaches to decision making which fall within

this type of process are those delineated by Wheeler and Janis (1980) and Arnold (1978). 


\section{Wheeler and Janis' Five-Stage Decision-Making Strategy}

Some decision processes merely present a list of steps or stages to be followed, with brief explanations of each point. Others present techniques for listing and analyzing the information gathered in order to better understand the positive and negative aspects of each alternative. Benjamin Franklin (cited in Wheeler and Janis, 1980) devised the latter type of system, in which he listed the pros and cons in columns, then weighed them to determine which solution should be chosen.

Wheeler and Janis (1980) have updated and greatly enlarged upon Benjamin Franklin's approach. Their book, A Practical Guide for Making Decisions, details their approach. which is based on the conflict model of decision making developed by Janis and Mann (1977). Wheeler and Janis base their methods on formal decision theory, but advocate the use of reasoning rather than numerical calculations in evaluating alternatives in personal decision making. Whereas formal decision analysis focuses solely on evaluation of alternatives, Wheeler and Janis begin with the indication of need for making a decision, and they work through to the final stage of adherence to the decision.

The five sequential stages which Wheeler and Janis detail are (1) accepting the challenge, or deciding to decide, (2) searching for alternatives, (3) evaluating the alternatives, (4) becoming committed to one of the alternatives, and (5) adhering to the decision in spite of the setbacks which inevitably occur. The major component of their approach is stage 3, evaluating alternatives. For this part of the process they recommend the use of a balance sheet, divided into four categories of lists: (1) tangible or utilitarian considerations for the decision maker. (2) tangible considerations for the decision maker's family, (3) selfapproval or -disapproval, including ethical considerations, and (4) approval or disapproval from others. This balance sheet can be a list of the positives and negatives for each area, or can be letter graded for each item, rating each alternative against the others. 
The approach of Wheeler and Janis is similar to that of John Arnold (1978), though it appears that Arnold's instrument would encourage more creativity in the generation of alternative solutions. Whereas the balance sheet begins with a list of alternatives and seeks to compare them against each other, Arnold begins with a set of absolute and desired objectives which are used to search for an alternative, and against which each alternative is then rated.

\section{Amold's Seven Building Blocks}

Arnold's (1978) decision-making instrument, which he calls the Seven Building Blocks, was developed for use in business and is based on the principles of formal decision theory. His approach falls within the scope of decision counseling, which refers to "the collaboration of consultant and client in diagnosing and improving the quality of the client's decisions" (Wheeler and Janis, 1980, p. 156)

The purpose of decision counseling is to facilitate clients in using their own resources to make the best decisions possible with respect to their personal values and objectives (Janis and Mann, 1977; Janis, 1982). Arnold believes that the success of a decision depends on a person's emotions, beliefs, values, and attitudes, as well as on logic and rationality. His approach provides people with an instrument for decision making which reflects their values, recognizes their expertise in knowledge of themselves and their situation, and provides a means of organizing their knowledge in a useable manner.

There are seven steps in Arnold's decision-making process, each of which requires answers to pertinent questions. These steps are as follows:

1. Smoke out the issues: Why is a decision necessary? What are the consequences of doing nothing? 
2. State your purpose: What needs to be determined? What do you want to decide? Why?

3. Set your criteria: What do you want to achieve, preserve, and avoid by whatever decision you make?

4. Establish your priorities: What are the criteria that any solution absolutely has to satisfy? What other criteria should it meet?

5. Search for solutions: How can you meet the criteria you have set?

6. Test the alternatives: How does each alternative stack up against the priorities?

7. Troubleshoot your decision: What could go wrong? How can your choice be improved?

According to VanGundy (1988),

A major obstacle to effective problem solving is development of an adequate problem definition. If a problem is inadequately defined at the outset of the problem-solving process, the probability of achieving an effective solution will be diminished. Since this initial perception of a problem often will determine how it will be approached during subsequent problem-solving stages, this stage is perhaps the most important of all the problem-solving stages (p. 12).

Arnold devotes considerable energy to the development of an adequate problem definition. Building blocks 1 and 2 help the decision maker delineate the issues involved in the decision and articulate precisely what he or she feels needs to be determined. The third and fourth building blocks guide the decision maker through the steps necessary to set criteria for the decision and to prioritize these criteria in a way that can help in the evaluation of the various alternatives generated in building block 5. The bulk of Arnold's strategy deals with the definition and analysis of the problem situation.

In step 6, testing the alternatives, Arnold uses a rating scale which is similar in purpose to Janis and Mann's (1977) decisional 
balance sheet. Arnold's instrument is more detailed than the balance sheet, however, and requires careful reflection in order to rate each item honestly. Testing the alternatives involves three steps. First, the decision maker uses a 1 to 10 scale to rate each alternative in the same way he or she rated each of the criteria. Next, the rating given the alternative is multiplied by the rating of each criterion, resulting in a value score indicating how each alternative scores for each criterion. Thirdly, the value scores for each alternative are added up to achieve a total score for that alternative, and the totals of all alternatives are compared. The easiest way to rate each of the alternatives is by means of a chart such as that seen in figure 1 .

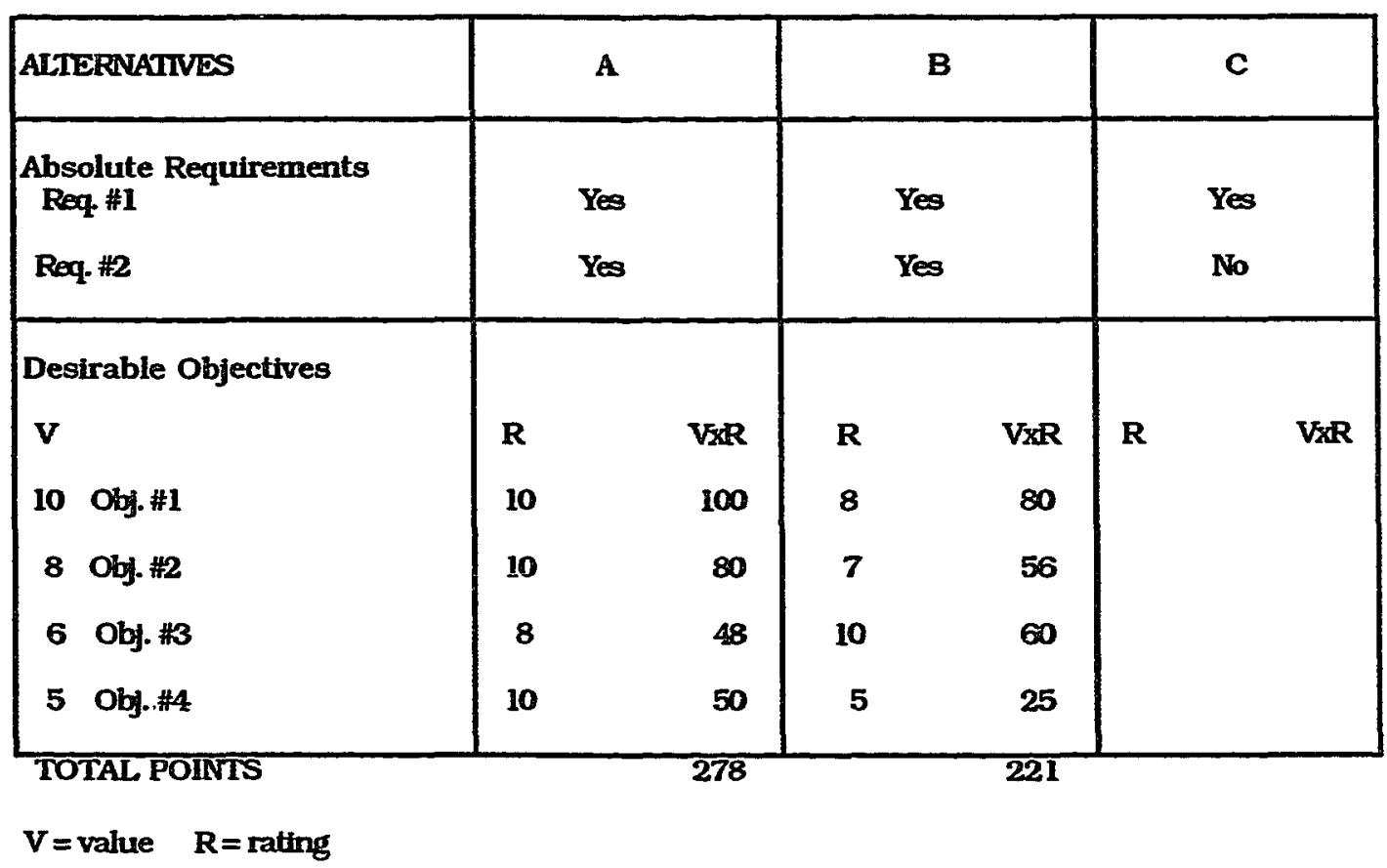

Figure 1. Alternative rating chart.

The winning alternative in figure 1 is obviously alternative $A$. Alternative $B$ may have been a good one, but did not score as well as $A$. 
Alternative $\mathrm{C}$, on the other hand, failed to meet the second absolute requirement so was no longer considered.

Arnold's alternative rating chart utilizes a common weighting system procedure which is useful to facilitate evaluation of different alternatives based on specific criteria. VanGundy (1988) points out that such a system produces a much more realistic assessment for problems involving the consideration of relative values of different criteria than does a procedure which considers all criteria to be of equal value. He cautions, however, that there is difficulty in quantifying value preferences, and that any measurement system is good only to the extent that it is based upon quality criteria and information. He suggests the use of journalistic Who. What, Where. When, Why, and How questions to increase the validity and quality of criteria. This is a technique which Amold also propounds. VanGundy further states that intuition or "gut feelings" should be considered in evaluating an alternative, a notion which Arnold states quite clearly in the beginning of his book (Arnold, $1978)$.

A review of related literature revealed no discussion of the effectiveness of the Seven Building Blocks, but numerous case studies throughout Arnold's books (Arnold, 1978; Arnold and Tompkins, 1982) document its effectiveness.

\section{CAREER DECISION-MAKING STUDIES}

\section{A Career Choice Class}

Cochran, Hetherington, and Strand's (1980) career choice class study supports the effectiveness of teaching decision-making skills in a classroom context. This study looked at the difference in effect of credit courses in career decision-making skills and in career orientation classes. The hypothesis was that, while students in both classes would 
show positive changes, students in the skills-oriented class would show greater change toward a higher overall decision-making stage as measured by the Vocational Decision-Making Checklist. The study's major finding was that a skills-oriented approach was indeed more effective in increasing career decision-making skill than was a career orientation approach. This study would seem to indicate that a skillsoriented decision-making instrument such as Arnold's Seven Building Blocks can be an appropriate tool to use in teaching students good decision-making skills.

\section{A Decision-Making Course}

Evans and Rector (1978) reported on the results of an evaluation of a college course entitled "Decision Making for Career Development." This course was designed to help undergraduate students in their educational and vocational decision making. This was done by having students examine alternative decision-making processes, explore various academic majors and careers, examine self-information relevant to career choices, and consider short- and long-term consequences of various majors and careers.

The subjects of the study included 79 freshmen and sophomores who were undecided about the choice of a major or a career. Students participated in the study through independent assignments, group meetings with the instructor, group meetings with a counselor, and personal conferences with the counselor.

The emphasis of the study was to determine if students would assess the course as helping them in selecting a major or career, if students felt the tasks included in the courses were helpful in their decision-making process, and if the course contributed positively to students' vocational development.

The results of this study showed that the decision-making course was indeed a contributing factor to the measured vocational 
development of the students. The researchers felt that the evaluation results "suggest that a combination of methods of counseling using personal contacts and group instruction is effective in facilitating career development among college students" (Evans and Rector, 1978, p. 168).

\section{SUMMARY}

A review of the literature has shown that there has been a great deal of research and writing concerning traditional college-age students, learning style theory, formal decision theory, and decision-making principles and processes. There are at least two well-delineated decision-making strategies which could conceivably be used to teach students good decision-making skills. Studies have also shown the effectiveness of teaching decision-making skills in a classroom context.

This review of the literature reveals that what is lacking is research regarding the use of specific step-by-step guides for decision making which counselors, advisers, and teachers could utilize in teaching students good decision-making skills, and which students could use effectively in making decisions. Also lacking in the literature is a means of identifying those students who would be likely to respond positively to such a decision-making method. This study seeks to provide information which can help to fill this gap in the literature. 


\section{CHAPTER III}

\section{RESEARCH PROCEDURES}

This study was designed to acquire data from traditional collegeage students regarding their attitude toward one decision-making tool. This investigation was conducted as a descriptive study. The methods used were a mixture of qualitative and quantitative techniques, looking at a broad spectrum of survey results and comparing them with essaystyle comments written by the same subjects. This chapter discusses the rationale for choosing a particular decision-making strategy, the research questions and hypotheses which form the basis for the study, the research methodology employed, the subjects who participated in the study, the instruments used, the variables analyzed, the field procedures followed, and the analysis of the data.

\section{RATIONALE FOR USING ARINOLD'S SEVEN BUILDING BLOCKS}

There are many areas in the decision-making literature which would lend themselves to interesting research studies. The decision to study one particular strategy for making decisions was made because of a desire to research one strategy which could be used to facilitate more effective student decision making. The two possible strategies which stood out in the review of literature were Wheeler and Janis' five stages of decision making and Arnold's Seven Building Blocks.

Arnold's strategy was chosen over that of Wheeler and Janis because of personal preference and because it appeared capable of 
engendering greater creativity in the generation of alternative solutions. It is a fairly comprehensive strategy and is one which the researcher has used in making personal decisions. The strategy incorporates a decision maker's feelings regarding the decision situation, but is quite rational in approach at the same time. This appealed to the researcher's bias that the use of rationality is desirable in making decisions. This strategy is value-laden in that it assumes that logical thinking is good in making decisions. Thus, it may not appeal to individuals who prefer to make decisions solely on the basis of intuition, emotion, or the desires and directives of others.

While the Seven Building Blocks probably will not appeal equally to everyone, they do appear to utilize good decision-making techniques which can be beneficial, at least to individuals who live in a democratic society. Even those who choose not to use the strategy in its entirety might be able to incorporate some aspects of it into their own repertoire of effective decision-making skills. This strategy may be less appropriate in a society based on group concensus and harmony than it is in an individualistic society such as that generally found in the United States. Counselors and advisers who choose to use this strategy need to be aware of the cultural differences in their students, as well as differences in individual learning and decision-making styles.

Borrowing Arnold's Seven Building Blocks from the world of business and applying it to individual decision making fits with Horan's call for sharing research and theory between fields. This instrument emphasizes the necessity of integrating values in the decision process, and incorporates a rating scale such as that advocated by Edwards and Fishburn (cited in Horan, 1979) in producing a value score used to compare alternatives. This strategy also looks at problems from a decision analysis viewpoint, evaluating alternatives on the basis of the likelihood of the possible consequences of each alternative and the decision maker's preference for the various consequences, and using desired objectives to generate possible alternatives. 


\section{RESEARCH GUESTIONS AND THEIR CORRESPONDING HYPOTHESES}

This study addresses three research questions. Eight hypotheses are related to these questions. These hypotheses were related to the examination of the attitudes of traditional college-age students toward the Seven Building Blocks decision-making strategy. Each hypothesis is presented in its null form $\left(\mathrm{H}_{\mathbf{O}}\right)$, which was tested statistically in this investigation, followed by a statement of the researcher's expected results for the study $\left(\mathrm{H}_{\mathrm{a}}\right)$. The hypotheses are here presented with the research questions to which they correspond.

1. Do the Seven Building Blocks appeal equally to traditional collegeage students with varying decision-making styles? If not, is there a pattern which might indicate that students with a particular decision-making style find this strategy more or less appealing?

$\mathrm{H}_{01}$ There is no significant difference between the attitude scores toward the Seven Building Blocks of individuals who gather information in a spontaneous manner and those who gather it systematically.

$\mathrm{H}_{\mathrm{a} 1}$ The Seven Building Blocks appeal to individuals who gather information in a systematic manner more than to those who gather it spontaneously.

$\mathrm{H}_{02}$ There is no significant difference between the attitude scores toward the Seven Building Blocks of individuals who analyze information internally and those who are external analyzers. 
$\mathrm{H}_{\mathrm{a} 2}$ The Seven Building Blocks appeal to individuals who analyze information internally more than to those who are external analyzers.

2. Is there an association between student attitude toward the Seven Building Blocks and age, gender, educational level, life responsibility status, attitude regarding decision making, and/or type of decision made using the strategy?

$\mathrm{H}_{\mathbf{0}}$ There is no significant difference between the attitude scores toward the Seven Building Blocks of students of varying ages.

$\mathrm{H}_{\mathrm{a}} 3$ There is a difference between the attitude scores toward the Seven Building Blocks of students of varying ages.

$\mathrm{H}_{04}$ There is no significant difference between the attitude scores toward the Seven Building Blocks of men and women.

$\mathrm{H}_{05}$ There is no significant difference between the attitude scores toward the Seven Building Blocks of students with varying educational levels.

$\mathrm{H}_{\text {a5 }}$ There is a difference between the attitude scores toward the Seven Building Blocks of students with varying educational levels.

$\mathrm{H}_{06}$ There is no significant difference between the attitude scores toward the Seven Building Blocks of 
students with greater life responsibilities and those with fewer life responsibilities.

$\mathrm{H}_{\text {a6 }}$ Greater appeal for the Seven Building Blocks is shown by students with greater life responsibilities (family, work, living situation).

$\mathrm{H}_{07}$ There is no significant difference between the attitude scores toward the Seven Building Blocks of students who attach a high level of importance to being good decision makers and students who value decision making at a low level.

$\mathrm{H}_{\mathrm{a}}$ A greater level of appeal for the Seven Building Blocks is shown by students who attach a high level of importance to being good decision makers than by students who value decision making at a low level.

$\mathrm{H}_{08}$ There is no significant difference between the attitude scores toward the Seven Building Blocks of students grappling with pressing decision situations and students without pressing decision situations.

$\mathrm{H}_{\mathrm{a} 8}$ More positive response toward the Seven Building Blocks is shown by students grappling with pressing decision situations than by students without pressing decision situations.

3. Which of the steps in the Seven Building Blocks do students perceive to be helpful? 


\section{RESEARCH METHODOLOGY}

Evidence suggests that decision-making research done in a laboratory suffers from a lack of external validity because of a lack of context, which is always present in real-world decision making (Ebbesen and Konecni, 1980). This study therefore used real-life decisions which subjects needed to make in order that the decision context and process would be as natural as possible. Follow-up interaction with subjects subsequent to the decision-making process was achieved through a brief questionnaire administered to all subjects. This should provide better evaluation of the effects of the decisionmaking instrument by giving input regarding the degree of satisfaction or post-decisional regret perceived by the subjects (see Horan, 1979, p. 225).

\section{SUBJECTS}

A total of 90 students were involved in the classes and seminars which formed the basis for this study. Exclusions on the basis of age or incomplete data resulted in a total of 62 subjects who were included in the sample population. The sample population ranged in age from 16 to 23 and was comprised of 35 women and 27 men, all of whom were enrolled in educational institutions in the state of Oregon at the time the study was conducted.

Fourteen of the subjects, 3 men and 11 women, were Portland State University students enrolled in the Winter 1989 section of a psychology class entitled "Improvement of Thinking." Seven men and 8 women were Oregon State University students involved in either Campus Crusade for Christ or the college Sunday school class at the First Baptist Church. These students attended one of two seminars on decision making given at the church in April, 1989. Four subjects, one 
woman and three men, were Linn-Benton Community College students taking a Winter 1989 course entitled "Career/Life Planning." Fifteen women and 14 men were enrolled in two upper class social science classes at West Albany High School in April, 1989.

Twenty-one of the subjects had completed at least two years of college at the time of the study. The remaining 41 subjects had completed less than two years of college, with 29 of those being high school students at the time the investigation was conducted.

All but two of the subjects were single. Six were living with a spouse or partner, 15 were living independently, and 41 were living with parents or other relatives. Most of the subjects were working, 37 part time and 6 full time. Thirty-three of the 62 subjects had already chosen their careers. A demographic profile of the subjects can be seen in Table $\mathbf{I}$.

Each of the four decision-making styles was represented in this study. Nine of the subjects (14.5\%) were spontaneous externals, 6 (9.7\%) were spontaneous internals, 28 (45.1\%) were systematic externals, and $19(30.7 \%)$ were systematic internals. While the number of spontaneous processors (24.2\%) was much lower than that of systematic processors (75.8\%), these findings are fairly consistent with the findings reported by Coscarelli (1983), who reported $81.4 \%$ of his sample to be systematic, and $18.6 \%$ to be spontaneous.

None of the subjects in this investigation attached a very low or low level of importance to being a good decision maker. Seven subjects felt decision making was of fair importance, 27 felt it was of a high level of importance, and 28 attached a very high level of importance to it. Most of the subjects (44) described themselves as being good or excellent decision makers, and most felt others see them as being good decision makers. Subjects' decision-making data is shown in Table II. 
TABLE I

DEMOGRAPHIC PROFLE OF THE SUBJECTS (N=62)

Class

Age

16

17

18

19

20

21

22

23

Gender

Female

Male

Educational Level

High School Graduate

Non High School Graduate

Years of College Completed

0

1

2

3

4

Educational Institution Portland State University Oregon State University Linn-Benton Comm. College West Albany High School

Marital Status

Single

Married

Living Situation

With Spouse/Partner

Independently

With Parents/Relatives

Work Situation

Not Working

Part Time

Full Time
Valid Missing Absolute Relative

Cases Cases Frequency Frequency

62

$\mathbf{0}$

$\begin{array}{rr}5 & 8.0 \\ 11 & 17.7 \\ 14 & 22.6 \\ 7 & 11.3 \\ 11 & 17.7 \\ 6 & 9.7 \\ 5 & 8.0 \\ 3 & 4.8\end{array}$

62

0

$35 \quad 56.5$

$27 \quad 43.5$

620

$33 \quad 53.2$

$29 \quad 46.8$

620

$32 \quad 51.6$

$8 \quad 12.9$

$10 \quad 16.1$

$8 \quad 12.9$

$3 \quad 4.8$

$1 \quad 1.6$

620

$14 \quad 22.6$

$15 \quad 24.2$

46.4

$29 \quad 46.8$

620

$60 \quad 96.8$

$2 \quad 3.2$

620

$\begin{array}{rr}6 & 9.7 \\ 15 & 24.2 \\ 41 & 66.1\end{array}$

$61 \quad 1$

$\begin{array}{rr}18 & 29.5 \\ 37 & 60.7 \\ 6 & 9.8\end{array}$


TABLE II

DECISION-MAKING PROFILE OF THE SUBJECTS (N=62)

Class

Decision-Making Style

Spontaneous External

Spontaneous Internal

Systematic External

Systematic Internal

Importance Attached to

Being a Good Decision Maker

Very Low

Low

Fair

High

Very High

$\begin{array}{cccc}\begin{array}{c}\text { Valid } \\ \text { Cases }\end{array} & \begin{array}{c}\text { Missing } \\ \text { Cases }\end{array} & \begin{array}{c}\text { Absolute } \\ \text { Frequency }\end{array} & \begin{array}{c}\text { Relative } \\ \text { Frequency }\end{array} \\ 62 & 0 & & \\ & & 9 & 14.5 \\ & & 6 & 9.7 \\ & & 29 & 45.1 \\ & & 19 & 30.7 \\ 62 & & & \\ & 0 & & \\ & & 0 & 0.0 \\ & & 0 & 0.0 \\ & & 7 & 11.3 \\ & & 27 & 43.5 \\ & & 28 & 45.2\end{array}$

Subjects were chosen in one of two ways. Some participated in the study as part of their normal course work for classes at Portland State University, Linn-Benton Community College, and West Albany High School. The Oregon State University students were invited to participate in a free decision-making seminar offered at the First Baptist Church of Corvallis. They attended on a voluntary basis.

\section{INSTRUMENTS}

The instruments used in this study were the Decision Making Inventory (Johnson, Coscarelli, and Johnson, 1983), questionnaires designed specifically for this study, and a 10-page handout detailing the Seven Building Blocks strategy. The Decision Making Inventory was administered at the outset of the study, followed by the first questionnaire. The second questionnaire was administered at the 
conclusion of the study. The Seven Building Blocks handout was given to students during the course of learning about the strategy. They used it as a worksheet in making their decisions, then retained it as a record of what they had learned through the study.

\section{The Decision Making Inventory}

The Decision Making Inventory (DMI) assesses the dimensions of Johnson's (1978) decision-making theory. The DMI is self-administered and can also be self-scored. It is an inventory designed to identify a person's preferred style of decision making (Coscarelli, 1983). It uses a Likert response format, and includes 20 items. The highest score in the information gathering subscales (spontaneous or systematic) is paired with the highest score in the information analyzing subscales (internal or external) to identify an individual's preferred decision-making style (e.g., systematic external).

Items 2, 7, and 11 on the DMI show how spontaneous a person is. Items 14, 18, and 20 reveal a systematic style. Internality is scored by answers to items 6,15 , and 17 , and externality is shown by items 3,4 , and 10. The remaining items on the 20-item inventory are filler items. Each of these items is scored by means of a scale with each choice being awarded a number as follows:

$\begin{array}{llllllllll}\text { NEVER } & - & 1 & 2 & 3 & 5 & 6 & 7 & - & \text { ALWAYS }\end{array}$

The absence of a " 4 " on the scale forces a choice toward one style or another. An individual's score for each scale is the total of the scores for that scale. A tie on the spontaneous-systematic dimension is awarded a score of " 1 " on the systematic, since a spontaneous will usually decide on an issue, one way or another and a systematic will tend to a balanced position. A tie on the internal-external dimension is given a " 1 " on the external scale. since test taking is biased toward internal processors (Coscarelli, 1983). 
The DMI was designed to help people understand their own decision-making characteristics, as well as the characteristics of others. It was developed with college undergraduates, but informal testing has shown that it can work with junior and senior high students and with adults. Mitchell (1985) reports reliability data and norms of means and standard deviations for college students only. He also lists the DMI as being appropriate for use with high school students. (See Appendix A for the Decision Making Inventory.)

\section{The Decision Making Questionnaire}

The Decision Making Questionnaire was developed by the researcher specifically for this study. The initial questionnaire items were reviewed by five educators and two college students. Their advice was followed in the modification of these items for the final form of the questionnaire.

The primary purpose of this initial questionnaire was to gather demographic data about the subjects. Questions were also included regarding subject attitude toward decision making and information about subjects' decision-making strategies. (See Appendix B for the Decision Making Questionnaire.)

\section{The Response to Amold's Seven Building Blocks Questionnaire}

The Response to Arnold's Seven Building Blocks Questionnaire was developed by the researcher specifically for this study using the same process as that used for the design of the Decision Making Questionnaire.

Questions in the Response to Arnold's Seven Building Blocks Questionnaire were designed to evaluate subjects' feelings about the strategy and their attitude toward it; to ascertain the kind of decision which was being worked on, its importance. and the level of stress 
associated with it; to determine how helpful subjects felt each of the steps of the strategy was and which ones they intended to incorporate into their own decision-making strategies; and to determine subjects' reactions to the Seven Building Blocks and changes they would like to see made in the strategy. (See Appendix $C$ for the Response to Arnold's Seven Building Blocks Questionnaire.)

\section{The Seven Building Blocks Handout}

Information for the Seven Building Blocks handout was taken directly from John Arnold's book, The Art of Decision Making (1978). Questions were used verbatim as given in the book. Since the 10-page handout was synthesized from an entire book, many instructions were condensed by the researcher. Thus, the handout represents the researcher's interpretation of Arnold's decision-making strategy. Parts of the handout were written for a colloquium paper. These instructions were then incorporated into the initial 12-page version of the handout, which was critiqued by two college students and five professional colleagues. Further modification from their input resulted in the final 10-page form of the handout.

The handout gives a brief overview of the strategy on page one. The remainder of the pages are worksheets which ask students questions, then provide spaces for appropriate answers. These worksheets guide students through the seven steps of the decisionmaking strategy. (See Appendix D for the Seven Building Blocks handout.) 
THE VARHABLES

\section{The Independent Variables}

The independent variables analyzed in this study were the decision-making styles of the subjects, age, gender, family responsibility status, attitude regarding the importance of being a good decision maker, and type of decision situation.

Students' decision-making styles were identified by administering the Decision Making Inventory (Johnson, Coscarelli, and Johnson, 1983). Each student received a score categorizing his or her decisionmaking style as being spontaneous internal, spontaneous external, systematic internal, or systematic external. Family responsibility status was determined by students' answers to questions concerning marital status, children, and living situation (see questions 10, 11, and 12 on the Decision Making Questionnaire in the Appendix). Attitude regarding the importance of being a good decision maker was self-reported as being very low, low, fair, high, or very high. The resulting data were condensed into three categories of attitude toward decision making: fair, high, and very high. This was done by deleting the very low and low categories, which were not circled by any of the respondents. The majority of respondents circled either high or very high. Type of decision situation was determined by analyzing student responses to questions concerning the perceived importance of the decision and the level of stress associated with making the decision.

\section{The Dependent Variable}

The dependent variable in this study was student attitude toward Arnold's Seven Building Blocks decision-making strategy. This attitude was determined by adding together the scores for students' responses to two questions on the Response to Arnold's Seven Building Blocks 
Questionnaire. Question 6 asked, "Now that you have used the Seven Building Blocks in working on a decision, what are your feelings about the strategy?" Possible responses were "Not enthusiastic," "Somewhat enthusiastic," and "Very enthusiastic." Question 13 asked, "How do you feel about the process you went through in making a decision using the Seven Building Blocks?" Response choices were "Dissatisfied," "Slightly dissatisfied," "Somewhat satisfied," and "Highly satisfied."

Corroboration of the attitude scores was designed to be ascertained through questions which probed the following areas: perceived effectiveness of the strategy, perceived thoroughness of the strategy, initial level of interest felt toward the strategy, satisfaction with decisions made using the strategy, the part played by the strategy in making a decision, perceived helpfulness of each step in the process, intention to use the strategy in further decision making. personal reactions to the strategy, and changes recommended to enhance the effectiveness of the strategy. (See questions $2,3,4,5,14,17,18,19$, and 20 on the Response to Arnold's Seven Building Blocks Questionnaire in Appendix C.) Attitude scores will be discussed further in the beginning of chapter IV.

\section{FIELD PROCEDURES}

At the outset of the study, subjects were given a brief explanation of the purpose of the study, what it would involve, and what would be required of them. Informed consent forms were distributed and explained, then were signed by subjects and returned to the researcher. Confidentiality of all information was assured, and any questions subjects had were answered.

Subjects were next given a 10-minute front-end Decision Making Inventory to determine their decision-making style, then participated in two hours of training and guidance in the use of Arnold's Seven Building 
Blocks decision-making strategy. This training included a short questionnaire eliciting demographic data and information concerning the strategy they currently used for making decisions; instruction about Arnold's decision-making strategy; a handout guiding students in using the strategy: guidance in using the strategy for making a decision which they were needing to make: and a questionnaire regarding their perception of the effectiveness and thoroughness of the instrument, how they would rate it against their prior decision-making strategies, perceived usefulness of the various steps of the Seven Building Blocks, resistance they felt to the use of the instrument, and their overall reactions to the entire experience.

At the end of the procedures, results of the Decision Making Inventory were given and explained, and subjects were asked whether or not the results of the inventory appeared to them to have validity.

\section{ANALYSIS OF DATA}

Data were collected by means of the Decision Making Inventory, the Decision Making Questionnaire, and the Response to Arnold's Seven Building Blocks Questionnaire. The data collected were analyzed to discover which subjects perceived Arnold's decision-making strategy as being useful, and whether there was any significant difference in attitude toward the strategy based on subjects' decision-making styles, age, gender, educational level, life responsibility status, and attitude regarding the importance of being a good decision maker.

Descriptive statistics were used to describe the respondents and their comments regarding their reactions to the decision-making strategy.

Statistical analyses involving chi-square tests implemented by contingency tables were used to ascertain the level of association 
between variables. Some of the data were collapsed for this process. Since analyzing the data for ages 16 to 23 would have yielded poor chi square results for the sample size used in this study, the decision was made to classify ages into three groups. Ages 16 and 17 constituted one group, ages 18 to 20 were a second group, and ages 21 to 23 were the third group. Data regarding educational level was also collapsed due to sample size. Thus, subjects with less than two years of college completed were in one group and subjects with two or more years completed were in another group.

The results of the chi square test analyzing the association between attitude toward the Seven Building Blocks and decision-making style were statistically significant ( $p=0.011$ ), but $58 \%$ of the cells had expected counts less than 5 . The style data were, therefore, collapsed in order to analyze the association between attitude and the various decision-making dimensions (spontaneous/systematic and internal/ external).

The findings of this investigation are presented in chapter IV as a descriptive study of the instrument, the subjects, the relationship between the subjects' decision-making styles and their view of the instrument, the relationship between each of the other variables and perception of the instrument, and the process of conducting this study. 


\section{CHAPTER IV}

\section{FINDINGS}

This investigation was conducted to examine the attitudes of traditional college-age students toward the Seven Building Blocks decision-making strategy in order to ascertain distinguishing characteristics of students who are most likely to respond to this tool in a positive manner. This chapter presents the findings of the study, the implications which the study has for the field of education, and proposed applications of the results of the research.

Data for this study were collected on 62 subjects in one high school and three college settings. All subjects were enrolled in Oregon educational institutions, 29 at West Albany High School in Albany, 14 at Portland State University in Portland, 4 at Linn-Benton Community College in Albany, and 15 at Oregon State University in Corvallis. All 62 subjects were between the ages of 16 and 23. All subjects received the same instruction regarding the decision-making strategy. Due to varying settings, 47 subjects received instruction in two separate one-hour class periods while 15 subjects received instruction in one of two two-hour seminars. Total instruction time for all subjects was approximately two hours.

Attitudes toward the Seven Building Blocks were examined by means of student response to a number of questions in the Response to Arnold's Seven Building Blocks Questionnaire. For the purposes of statistical analyses, an attitude score was constructed for each subject by adding together the scores from the two questions (questions 6 and 13) which specifically related to student feelings about using the strategy. 
This resulted in scores ranging from a low of 2 to a high of 7. Scores of 2 or 3 were grouped together as a low attitude score. Scores of 4 or 5 were labeled as a medium score. A high attitude score was shown by a score of 6 or 7 .

Corroboration of the attitude scores was sought by analyzing student answers to questions regarding effectiveness and thoroughness of the strategy, initial interest felt toward the strategy, satisfaction with decisions made using the strategy, the part the strategy played in making a decision, the helpfulness of each step, the intention to incorporate parts of the strategy in personal decision-making techniques, personal reactions to the strategy, and changes recommended to enhance the strategy's effectiveness. In looking at the data, however, it was evident that many students felt the strategy was effective, thorough, and somewhat helpful, but did not feel it was a tool which they wanted to use. The decision was therefore made to construct attitude scores solely on the basis of student response to questions regarding how students felt about the strategy and about the process they went through in making a decision with the strategy. This decision was backed up by student essay-style comments to questions concerning reactions to the Seven Building Blocks and changes which they would like to see made in the strategy. These comments are listed in Appendix $\mathrm{H}$.

The primary purpose of this study was to identify student characteristics which could predict those students who are most likely to respond in a positive manner to the Seven Building Blocks decisionmaking strategy. The chi square test of independence was used to determine whether or not a statistically significant association exists between student attitude toward the Seven Building Blocks and each of the student characteristic variables. The .05 level of significance was utilized to determine whether to retain or reject each of the null hypotheses. Eight hypotheses were tested using the chi square test of independence. 
The results of the analyses are organized around the three research questions. The first two hypotheses relate to the first research question. The remaining six hypotheses relate to the second question. Both the null hypotheses $\left(\mathrm{H}_{\mathrm{O}}\right)$ and the researcher's expected findings, stated as alternative hypotheses $\left(\mathrm{H}_{\mathrm{a}}\right)$, will be given and discussed.

Findings for the third research question were determined by adding together the scores from student responses to questions 14,15 , and 16 on the Response to Arnold's Seven Building Blocks Questionnaire (see Appendix C). Question 14 asked students to rate each of the Building Blocks as being not helpful, helpful, or very helpful. Questions 15 and 16 asked students to circle the most and least helpful Building Blocks respectively.

The findings will be presented for each of the variables studied and discussed in relation to the research questions.

\section{THE ASSOCIATION BETWEEN ATTITUDE TOWARD THE SEVEN BUHDING BLOCKS AND DECISION-MAKING STYLE}

Do the Seven Building Blocks appeal equally to traditional college-age students with varying decision-making styles? If not, is there a pattern which might indicate that students with a particular decision-making style find this strategy more or less appealing?

Analysis of the association between attitude toward the Seven Building Blocks and decision-making style resulted in a chi square of 16.525 with 6 degrees of freedom and a statistically significant probability of 0.011 . This may not have been a valid test, however, since $58 \%$ of the cells had expected counts less than 5. Therefore, further tests were run which looked at the association between attitude score 
and the spontaneous/systematic and internal/external dimensions of decision-making styles.

\section{The Spontaneous and Systematic Dimensions}

$\mathrm{H}_{01}$ There is no significant difference between the attitude scores toward the Seven Building Blocks of individuals who gather information in a spontaneous manner and those who gather it systematically.

$\mathrm{H}_{\mathrm{al}}$ The Seven Building Blocks appeal to individuals who gather information in a systematic manner more than to those who gather it spontaneously.

The association between attitude toward the Seven Building Blocks and the spontaneous and systematic dimensions of decisionmaking style was analyzed by means of a chi square test. The results were statistically significant at the .05 level $(p=0.001)$ with 2 degrees of freedom and a value of 14.706, as can be seen in Table III. The null hypothesis was therefore rejected.

Discussion: The results of this test indicated that there is indeed a difference in attitude toward the Seven Building Blocks between spontaneous and systematic analyzers, and that more positive attitudes were shown by those who analyze systematically.

From a total of 15 spontaneous analyzers, $8(53.3 \%)$ had a low attitude score regarding the Building Blocks, 5 (33.3\%) had medium scores, and only 2 (13.3\%) had high attitude scores.

Systematic analyzers scored in a much more positive manner toward the strategy. Only 4 of the $47(8.5 \%)$ had a low attitude score, $28(59.6 \%)$ had a medium score, and 15 (31.9\%) had a high attitude score regarding the Building Blocks. 
TABLE III

ASSOCLATION OF ATTITUDE SCORES WITH SPONTANEOUS AND SYSTEMATIC DECISION-MAKING DMIENSIONS

\begin{tabular}{lccc}
\hline Attitude & \multicolumn{2}{c}{ Decision-Makcing Dimensions } \\
Spontaneous & Systematic & Total \\
\hline Low & 8 & 4 & 12 \\
Medium & 5 & 28 & 33 \\
High & 2 & 15 & 17 \\
& & & 62 \\
\hline Total & 15 & 47 & \\
\hline
\end{tabular}

Chi square $=14.706, \mathrm{df}=2, \mathrm{p}=0.001$

These findings are in keeping with the researcher's hypothesis that the Seven Building Blocks appeal to individuals who gather information in a systematic manner more than to those who gather information spontaneously.

\section{The Internal and Extermal Dimensions}

$\mathrm{H}_{02}$ There is no significant difference between the attitude scores toward the Seven Building Blocks of individuals who analyze information internally and those who are external analyzers.

$\mathrm{H}_{\mathrm{a} 2}$ The Seven Building Blocks appeal to individuals who analyze information internally more than to those who are external analyzers. 
The association between attitude toward this decision-making strategy and the internal and external decision-making dimensions was analyzed by means of chi square. The results did not achieve the .05 level of significance, as can be seen in Table IV. The null hypothesis was retained.

TABLE IV

ASSOCIATION OF ATTITUDE SCORES WITH INTERNAL AND EXTERNAL DECISION-RARTING DIMENSIONS

\begin{tabular}{lccc}
\hline & \multicolumn{2}{c}{ Decision-Making Dimensions } \\
Attitude & Internal & External & Total \\
\hline Low & 5 & 7 & 12 \\
Medium & 14 & 19 & 33 \\
High & 6 & 11 & 17 \\
& & & 62 \\
\hline \hline
\end{tabular}

Chi square $=0.248, \mathrm{df}=2, \mathrm{p}=0.883$

Discussion: The results of this test indicated no statistically significant difference in attitude toward the Seven Building Blocks based on the internal and external dimensions of decision-making styles. The evidence shows that, within the scope of this investigation, internality and externality had little or no effect upon students' attitudes toward this decision-making strategy.

The percentage of subjects for each dimension who had low attitude scores was nearly identical, with $20 \%$ of internals and $19 \%$ of externals having scores of 2 or 3 . $56 \%$ of internals and $51 \%$ of externals 
had medium scores. Contrary to the researcher's stated hypothesis, $30 \%$ of externals had high attitude scores, while only $24 \%$ of internals achieved high scores.

\section{Semmory}

In analyzing the data to determine the association between attitude toward the Seven Building Blocks and decision-making style, no significant association was observed between attitude score and the internal and external dimensions. The association between attitude and the spontaneous and systematic dimensions, however, was much greater than what could be expected by chance. This finding was significant at the $p=0.001$ level, which indicates a marked difference between the attitudes of spontaneous and systematic information gatherers.

The study showed that $53.3 \%$ of the spontaneous analyzers had low attitude scores, $33.3 \%$ had medium scores, and only $13.3 \%$ had high scores. Systematics scored much higher in attitude, with $31.9 \%$ having a high score of 6 or $7,59.6 \%$ having medium scores of 4 or 5 , and only $\mathbf{8 . 5 \%}$ having low attitude scores.

The findings regarding the spontaneous and systematic dimensions were in keeping with speculation at the outset of the study. It was hypothesized that systematics would react more favorably toward the Building Blocks because of their deliberate manner of assembling facts and analyzing them. The spontaneous tendency to evaluate things globally rather than looking at component parts would seem to fit less well with Arnold's logical and systematic strategy of decision-making.

The finding that there was no significant difference in appeal with regard to internality and externality was somewhat surprising. Since the Seven Building Blocks were presented in a class format which would appear to favor internal processing rather than vocalizing, it was hypothesized that internal processors would respond more favorably than externals. That this was not the case could perhaps be attributed 
to the fact that externals have had to adapt to some degree to the classroom setting by learning to think silently, even though their preferred method is to think aloud.

\section{THE ASSOCIATION BETWEEN ATTITUDE TOWARD THE} SEVEN BUILDING BLOCKS AND OTHER VARIABLES

Is there an association between student attitude toward the Seven Building Blocks and age, gender, educational level. level of independence and family responsibility, work situation, attitude regarding decision making, and/or type of decision made using the strategy?

Age

$\mathrm{H}_{03}$ There is no significant difference between the attitude scores toward the Seven Building Blocks of students of varying ages.

$\mathrm{H}_{\mathrm{a} 3}$ There is a difference between the attitude scores toward the Seven Building Blocks of students of varying ages.

A chi square test of independence showed no significant level of association between age and attitude toward the Seven Building Blocks (chi square $=4.472, p=0.346$ ), as can be seen in Table $V$. The null hypothesis was retained.

Discussion: The results of this test indicated no significant difference in attitude toward the Seven Building Blocks based on age. $31.3 \%$ of the 16- to 17 -year olds had low attitude scores and only $12.5 \%$ of them had high scores. $15.6 \%$ of the 18 - to 20 -year olds had low 
scores, while $28.1 \%$ had high scores. Only $14.3 \%$ of the 21 - to 23 -year old group had low scores and $\mathbf{4 2 . 9 \%}$ of them had high attitude scores. Thus, there were fewer high attitude scores and more low attitude scores in the 16- to 17-year old group when compared with the 21- to 23- year old group. While these differences are interesting, the statistical analysis did not show that the differences were greater than could be attributed to chance.

\section{TABLE V}

ASSOCIATION OF ATTITUDE SCORES WITH AGE CLASSIFICATION

\begin{tabular}{lcccc}
\hline & \multicolumn{5}{c}{ Age Classification } \\
Attitude & $16-17$ & $18-20$ & $21-23$ & Total \\
\hline Low & 5 & 5 & 2 & 12 \\
Medium & 9 & 18 & 6 & 33 \\
High & 2 & 9 & 6 & 17 \\
\hline Total & 16 & 32 & 14 & 62 \\
\hline
\end{tabular}

Chi square $=4.472$, $\mathrm{df}=4, \mathrm{p}=0.346$

\section{Gender}

$\mathrm{H}_{04}$ There is no significant difference between the attitude scores toward the Seven Building Blocks of men and women.

The association between attitude toward the Seven Building Blocks and gender was analyzed by means of a chi square test. As can be 
seen in Table VI, the results were not statistically significant $(\mathrm{p}=$ 0.942), and the null hypothesis was retained.

TABLE VI

ASSOCIATION OF ATTITUDE SCORES WITH GENDER

\begin{tabular}{|c|c|c|c|}
\hline \multicolumn{4}{|c|}{ Gender } \\
\hline Attitude & Female & Male & Total \\
\hline Low & 7 & 5 & 12 \\
\hline Medium & 19 & 14 & 33 \\
\hline High & 9 & 8 & 17 \\
\hline Total & 35 & 27 & 62 \\
\hline
\end{tabular}

Chi square $=0.119, \mathrm{df}=2, \mathrm{p}=0.942$

Discussion: It was hypothesized at the outset of the study that there would be no significant difference in attitude toward the Seven Building Blocks on the basis of gender, and, indeed, this proved to be the case. Scores were nearly identical to expected scores for each of the cells. Low scores were achieved by $20 \%$ of the women and $18.5 \%$ of the men. High scores were achieved by $25.7 \%$ of the women and $29.6 \%$ of the men. Thus, the men were slightly more positive toward the strategy, but not enough to be statistically significant. 


\section{Educational Level}

$\mathrm{H}_{05}$ There is no significant difference between the attitude scores toward the Seven Building Blocks of students with varying educational levels.

$\mathrm{H}_{\mathbf{a}} 5$ There is a difference between the attitude scores toward the Seven Building Blocks of students with varying educational levels.

The association between attitude scores toward the Seven Building Blocks decision-making strategy and educational level was analyzed by means of three chi square tests. The first test looked at the differences between attitudes of high school students and college students. The results of this test were statistically significant (chi square $=7.572, \mathrm{df}=2, \mathrm{p}=0.03$ ), as can be seen in Table VII.

TABLE VII

ASSOCIATION OF ATTITUDE SCORES WITH EDUCATIONAL LEVEL (HIGH SCHOOL AND COLLEGE)

\begin{tabular}{lccc}
\hline & \multicolumn{2}{c}{ Educational Level } & \\
Attitude & High School & College & Total \\
\hline Low & 9 & 3 & 12 \\
Medium & 16 & 17 & 33 \\
High & 4 & 13 & 17 \\
\hline \hline Total & 29 & 33 & 62 \\
\hline
\end{tabular}

Chi square $=7.572, \mathrm{df}=2, \mathrm{p}=0.03$ 
The second test reclassified subjects into one group of students with less than one year of college experience and one group of students with more than one year of college. The results of this test were also statistically significant (chi square $=6.097$, df $=2, p-0.047$ ), though the results were not quite as striking as the first test. These results are shown in Table VII.

TABLE VIII

ASSOCLATION OF ATTITUDE SCORES WITH EDUCATIONAL LEVEL CLASSIFICATION (O AND I OR MORE YEARS)

\begin{tabular}{lccc}
\hline & $\begin{array}{c}\text { Educational Level } \\
\text { Attitude }\end{array}$ & (Years of College Completed) & \\
Low & 9 & 1 or More Years & Total \\
Medium & 18 & 15 & 12 \\
High & 5 & 12 & 33 \\
& & & 17 \\
Total & 32 & 30 & 62 \\
\hline
\end{tabular}

Chi square $=6.097, \mathrm{df}=2, \mathrm{p}=0.047$

Finally, a chi square was done to analyze the difference between those who had 0 to one year of college experience and those who had at least two years of college experience. The results of this chi square test of association between attitude scores and educational level was statistically significant at the .05 level $(p=0.007)$ with 2 degrees of freedom and a value of 9.999 . These results were the most significant of the three tests and are shown in Table $\mathrm{XX}$.

On the basis of these tests, the null hypothesis was rejected. 
TABLE IX

ASSOCIATION OF ATTITUDE SCORES WTH EDUCATIONAL LEVEL CLASSIFICATION (O - 1 YEAR AND 2 OR MORE YEARS)

\begin{tabular}{|c|c|c|c|}
\hline \multicolumn{4}{|c|}{ Educational Level (Years of College Completed) } \\
\hline Attitude & 0 - 1 Year & 2 or More Years & Total \\
\hline Low & 9 & 3 & 12 \\
\hline Medium & 26 & 7 & 33 \\
\hline High & 6 & 11 & 17 \\
\hline Total & 41 & 21 & 62 \\
\hline
\end{tabular}

Chi square $=9.999, \mathrm{df}=2, \mathrm{p}=0.007$

Discussion: This test shows that there is a difference in attitude toward the Seven Building Blocks based on educational level, and that more positive attitudes are shown by those with more education.

Because educational levels ranged from no college experience at all to 5 years of college completed, it was necessary to collapse the data for the purpose of statistical analysis. Of the 62 subjects, 29 were high school students and 33 were college students. Chi square tests of association revealed statistically significant differences in attitude between high school and college students. The findings showed, however, that the greatest differences in attitude were observed between those who had completed less than two years of college and those who had completed more than two years of college.

In the 0-1 year of college group, 9 subjects $(22 \%)$ had a low attitude score toward the Seven Building Blocks. 26 subjects (63.4\%) had medium scores and $6(14.6 \%)$ had high scores. 
In the 2 or more years of college group, only 3 subjects (14.3\%) had low attitude scores, 7 (33.3\%) had medium scores, and 11 (52.4\%) had high scores.

The finding that educational level plays a part in attitude toward the Seven Building Blocks was anticipated in this investigation; however, the results were surprisingly marked. It was very apparent that those subjects with little or no college experience felt that this strategy was unnecessarily long and involved. Some of the comments of the subjects in this group included the following: "I thought that it was way too drawn out \& boring." "It was way too much to go through just to make a decision. A person doesn't usually have to go through all of that just to reach a decision. Most of us make up our minds very quickly and easily." "It was to (sic) long to make a decision. They put to (sic) much stress on a person." "Make it shorter."

On the other hand, comments from the group with two or more years of college included the following: "It helped me look at a few alternatives that $I$ had previously ruled out, and to give them a fair shake. It made me think about where my priorities are. It's a thought provoking guideline that's useful." "It gives me a good systematic way to make decisions." "I liked them-- a little complex for some decisions, but it's a good system for the big, important issues." (For a complete listing of student comments regarding the Seven Building Blocks, listed by educational level and decision-making style, see Appendix $\mathbf{H}$.)

\section{Life Responsibility Status}

$\mathrm{H}_{06}$ There is no significant difference between the attitude scores toward the Seven Building Blocks of students with greater life responsibilities and those with fewer life responsibilities. 
$\mathrm{H}_{\text {a6 }}$ Greater appeal for the Seven Building Blocks is shown by students with greater life responsibilities (family, work, living situation).

The association between attitude toward the Seven Building Blocks and life responsibility status was tested by means of chi square tests. Only two of the 62 subjects were married, so marital status did not show any statistical significance. Only two subjects had children, so that also did not have any appreciable effect. Analysis of living situation showed some deviation from the expected frequency in some of the cells, but did not reach a level of statistical significance ( $p=0.144$ ). Analysis of work situation did not show statistical significance ( $p=$ 0.498). Choice of a career also showed no statistical significance ( $p=$ $0.327)$.

While the analyses of living situation and work situation did not reach statistical significance, they did provide some interesting information which will be discussed.

The null hypothesis was retained.

Discussion: It was hypothesized at the outset of this investigation that there might be a difference in attitude toward the Seven Building Blocks based on life-related experience. The study did not bear this out, however. This may be in part due to the limited sample size, or to the large number of students still in high school.

Marital status and number of children had no appreciable effect in this study, due to the limited number of subjects who were married and/or had children.

A look at subjects' living situations showed that two-thirds of the students (41) were living with parents or other relatives at the time the study was conducted. Six were living with a spouse or partner and the remaining 15 were living independently. It was interesting to note that, of the 15 living independently, 8 (53.3\%) had high attitude scores, 5 
(33.3\%) had medium scores, and only $2(13.3 \%)$ had low scores. Table $\mathrm{X}$ shows these results.

TABLE X

ASSOCIATION OF ATTITUDE SCORES WITH LIVING SITUATION

\begin{tabular}{lcccc}
\hline & \multicolumn{2}{c}{ Living Situation } & & \\
Attitude & $\begin{array}{c}\text { Parents/ } \\
\text { Relatives }\end{array}$ & $\begin{array}{c}\text { Spouse/ } \\
\text { Independently }\end{array}$ & Partner & Total \\
\hline Low & 9 & 2 & 1 & 12 \\
Medium & 24 & 5 & 4 & 33 \\
High & 8 & 8 & 1 & 17 \\
\hline \hline Total & 41 & 15 & 6 & 62 \\
\hline
\end{tabular}

Chi square $=6.844, \mathrm{df}=4, \mathrm{p}=0.144$

Sixty-one of the 62 subjects reported their work situation. Eighteen subjects (29.5\%) were not working at all, 37 (60.7\%) were working part time, and 6 (9.9\%) were working full time. While the number of full time workers was limited, it was interesting to note that none of them had a low attitude score toward the Seven Building Blocks. Three had medium scores and the other three had high scores. The results of this test can be seen in Table XI.

Twenty-six of the subjects $(44 \%)$ had not chosen a career yet. while $33(56 \%)$ had chosen a career. There was no apparent difference in attitude scores between the two groups. 
TABLE XI

ASSOCIATION OF ATTITUDE SCORES WITH WORK SITUATION

\begin{tabular}{|c|c|c|c|c|}
\hline \multirow[b]{2}{*}{ Attitude } & \multicolumn{3}{|c|}{ Work Situation } & \multirow[b]{2}{*}{ Total } \\
\hline & $\begin{array}{c}\text { Not } \\
\text { Working }\end{array}$ & $\begin{array}{l}\text { Working } \\
\text { Part Time }\end{array}$ & $\begin{array}{l}\text { Working } \\
\text { Full Time }\end{array}$ & \\
\hline Low & 5 & 7 & $\mathbf{0}$ & 12 \\
\hline Medium & 8 & 21 & 3 & 32 \\
\hline High & 5 & 9 & 3 & 17 \\
\hline Total & 18 & 37 & 6 & 61 \\
\hline
\end{tabular}

Chi square $=3.371 \mathrm{df}=4, \mathrm{p}=0.498$

\section{Attitude Regarding the Importance of Being a Good Decision Maker}

$\mathrm{H}_{07}$ There is no significant difference between the attitude scores toward the Seven Building Blocks of students who attach a high level of importance to being good decision makers and students who value decision making at a low level.

$\mathrm{H}_{\text {a7 }}$ A greater level of appeal for the Seven Building Blocks is shown by students who attach a high level of importance to being good decision makers than by students who value decision making at a low level.

The association between attitude toward this decision-making strategy and the level of importance attached to being a good decision maker was analyzed by means of chi square. As can be seen in Table XII, 
the results of the test were statistically significant at the .05 level $\mathrm{p}=$ 0.001 ) with 4 degrees of freedom and a value of 18.432. The null hypothesis was therefore rejected.

TABLE XII

ASSOCIATION OF ATTITUDE SCORES WITH IMPORTANCE ATTACHED TO BEING A GOOD DECISION MAKER

\begin{tabular}{|c|c|c|c|c|}
\hline \multirow[b]{2}{*}{ Attitude } & \multicolumn{4}{|c|}{ Importance of Being a Good Decision Maker } \\
\hline & Fair & High & Very High & Total \\
\hline Low & 5 & 4 & 3 & 12 \\
\hline Medium & 3 & 18 & 12 & 33 \\
\hline High & $\mathbf{0}$ & 4 & 13 & 17 \\
\hline Total & 8 & 26 & 28 & 62 \\
\hline
\end{tabular}

Chi square $=18.432, \mathrm{df}=4, \mathrm{p}=0.001$

Discussion: The chi square test of independence showed a marked difference in attitude toward the Seven Building Blocks by subjects who attached a high or very high level of importance to being a good decision maker when compared with students who felt being a good decision maker was only of fair importance.

Only eight of the subjects participating in this study felt that being a good decision maker was of fair importance. None of these had a high attitude score regarding the Seven Building Blocks. Five of them (62.5\%) had low attitudes and three (37.5\%) had medium scores. Of the 26 who valued being a good decision maker as being of high importance, 4 (15.4\%) had low scores, 18 (69.2\%) had medium scores, 
and 4 (15.4\%) had high scores. Only three (10.7\%) of the 28 subjects who attached a very high level of importance to being a good decision maker had low attitude scores. Twelve (42.9\%) had medium scores and 13 (46.4\%) had high scores.

These findings are in keeping with the hypothesis that a greater level of appeal for the Seven Building Blocks would be shown by students who attach a high level of importance to being good decision makers than by students who value decision making at a low level. The findings are not at all surprising, since students who value decision making highly are more likely to be interested in learning about a decision-making strategy and in applying it to a decision situation. Students who do not value decision-making skills very highly are likely to view learning a decision-making strategy as unnecessary and uninteresting.

\section{Type of Decision Situation}

$\mathrm{H}_{08}$ There is no significant difference between the attitude scores toward the Seven Building Blocks of students grappling with pressing decision situations and students without pressing decision situations.

$\mathrm{H}_{\mathrm{a} 8}$ More positive response toward the Seven Building Blocks is shown by students grappling with pressing decision situations than by students without pressing decision situations.

The association between attitude toward the Seven Building Blocks and the absence or presence of pressing decision situations was analyzed by means of two chi square tests. The first looked at the association between attitude and the degree of importance subjects attached to the decisions they were considering. This resulted in a chi square of 2.353 with 2 degrees of freedom and a probability of 0.308 . 
The second test analyzed the association between attitude and the level of stress subjects felt about the decision. This resulted in a chi square of 1.82 with 4 degrees of freedom and a probability of 0.769 . Thus, no association was found between attitude toward the Seven Building Blocks and the presence of pressing decision situations. The null hypothesis was retained.

Discussion: Evidence to support the researcher's hypothesis that a higher attitude score regarding the Seven Building Blocks would be achieved by subjects with pressing decision situations was not found in this study. This finding was somewhat surprising, since it was thought that students with pressing decisions would be more interested in learning about a decision-making strategy which they could apply to a situation in need of resolution than would students who felt their decision was less important. The results may be somewhat skewed. however, since no students indicated that their decision was not very important. All subjects felt that their decisions were either moderately important or very important.

Students were also asked what type of decision they were making using the Seven Building Blocks. Twenty-two stated they were working on educational decisions, 21 were making career decisions, 11 indicated they were working on personal or relationship decisions, three had financial decisions to make, three were making churchrelated decisions, and one subject was deliberating about marriage.

The finding that the majority of students were involved with making educational and career decisions is in keeping with Chickering and Havighurst's (1981) assertion that choosing and preparing for a career is the most challenging developmental task facing late adolescents and youth. and that it is the organizing center for the lives of most of the young men and women of this age group. 
SHinmany

The analysis of data regarding the association between student attitude toward the Seven Building Blocks and other variables revealed a number of interesting items. Some were anticipated, while others were rather surprising. Some showed no statistically significant difference, while others showed levels of statistical significance well below the .05 level of confidence.

No statistical significance was seen in this investigation when looking at the association between attitude toward the decision-making strategy studied and age, gender, marital status, number of children, status of having chosen or not chosen a career, or absence or presence of a pressing decision situation.

The chi square tests for association between attitude toward the Seven Building Blocks and living situation or work situation also failed to achieve statistical significance; however, these two areas did reveal some interesting information. of those subjects who were living independently at the time of the study, 53.3\% had high attitude scores toward the strategy and $33.3 \%$ had medium scores. Only $13.3 \%$ of them had low scores. These unusually positive attitudes may show a difference which this study could not fully analyze. Further research in this area should be done to ascertain whether or not traditional college-age students who live independently face more decision situations for which they are personally responsible than those students who live with parents, relatives, spouses, or partners. A higher level of responsibility could account for the difference in attitude scores.

The data regarding the association between attitude scores and work situation showed that, of those students who were working full time, no low scores were reported. Half of the full time workers had medium scores and half of them had high scores. Once again. further research would need to be done to analyze the possible relationship between full time work and attitude toward the Seven Building Blocks. 
and to determine whether or not this is associated with level of responsibility.

Statistical significance was achieved in analyzing the association between attitude toward the Seven Building Blocks and educational level and between attitude and the importance attached to being a good decision maker. In analyzing the data concerning educational level. subjects were assigned to one of two groups: those who had completed less than two years of college and those who had completed two or more years of college. Marked differences were seen in the scores for the two groups. Those with little or no college had much lower scores than those with at least two years of college. Of the upperclassmen, 52.4\% had high scores and $33.3 \%$ had medium scores. Only $14.3 \%$ had low scores. On the other hand, only $14.6 \%$ of the underclassmen had high attitude scores, while $63.4 \%$ had medium scores and $22 \%$ had low scores.

While the difference between educational classification groups was significant, it is important to note that the percentage of students overall who had low attitude scores toward the Seven Building Blocks was only $18.15 \%$. In other words, less than one in five traditional college-age students who participated in this study achieved a low attitude score toward the strategy. Thus, more than four out of five students had at least a medium attitude score regarding the strategy.

There was also a high level of association between attitude score and the importance attached to being a good decision maker. Those who felt it was important or very important to be a good decision maker tended to have higher attitude scores than those who only attached a fair level of importance to being a good decision maker. This was in keeping with the researcher's hypothesis. It was also an expected outcome. since a high level of interest in decision making would tend to engender greater interest in a specific decision-making strategy. 
STUDENT PERCEPTION OF THE HELPFULNESS OF THE VARIOUS STEPS IN THE SEVEN BUILDING BLOCKS

Which of the steps in the Seven Building Blocks do students perceive to be helpful?

Descriptive statistics were utilized to analyze the data regarding student perception of the helpfulness of each of the steps of the Seven Building Blocks. Findings for this research question were determined by totaling student responses to questions 14,15 , and 16 on the Response to Arnold's Seven Building Blocks Questionnaire. Question 14 asked students to rate each of the Building Blocks as being not helpful, helpful, or very helpful. Questions 15 and 16 asked students to circle the most and least helpful Building Blocks, respectively.

Each of the steps in the Seven Building Blocks was rated as being not helpful, helpful, or very helpful in Question 14. These categories were then given values of 0,1 , and 2, respectively. Thus, with 62 respondents, each step should have had a possible total of 124 points. Unfortunately, some respondents did not rate some of the steps. Therefore, the score for each step was totaled, then divided by the possible total according to the number of subjects who rated that step to arrive at a percentage score of the total possible score for each step. These scores are shown in Table XIII.

Discussion: Building Block 4, "Establish Your Priorities," was overwhelmingly seen as being the most helpful step. Seven of the 13 spontaneous processors and 21 of the 46 systematics identified Block 4 as the most helpful in their view. Building Block 1, "Smoke Out the Issues," was seen by the majority as the least favorite of the steps. Four out of 13 spontaneous processors and 17 out of 44 systematics labeled it as the least helpful. Table XIV shows the Building Blocks in the order of perceived helpfulness. Blocks 5 and 7 tied for fifth place. 
TABLE XIII

PERCENTAGE OF THE POSSIBLE VOTE FOR EACH OF THE SEVEN BUILDING BLOCKS

Building Block

Percentage Score

Building Block 1: "Smoke Out the Issues"

$(54 / 120) \quad 45.0 \%$

Building Block 2: "State Your Purpose"

$(69 / 124) \quad 55.6 \%$

Building Block 3: "Set Your Criteria"

$(82 / 124) \quad 66.1 \%$

Building Block 4: "Establish Your Priorities"

(91/122) $74.6 \%$

Building Block 5: "Search for Solutions"

$(58 / 120) \quad 48.3 \%$

Building Block 6: "Test the Alternatives"

$(67 / 120) \quad 55.8 \%$

Building Block 7: "Troubleshoot Your Decision" (58/120) $\quad 48.3 \%$

TABLE XIV

ORDER OF PERCEIVED HELPFULNESS OF THE SEVEN BUILDING BLOCKS

\begin{tabular}{cl}
\hline Ranking & \multicolumn{2}{c}{ Building Block } \\
\hline 1 & Building Block 4: "Establish Your Priorities" \\
2 & Building Block 3: "Set Your Criteria" \\
3 & Building Block 6: "Test the Alternatives" \\
4 & Building Block 2: "State Your Purpose" \\
5 & Building Block 5: "Search for Solutions" \\
5 & Building Block 7: "Troubleshoot Your Decision" \\
6 & Building Block 1: "Smoke Out the Issues" \\
\hline
\end{tabular}

There appeared to be a distinct difference in student views of the various Building Blocks. Building Blocks 2, 3, 4, and 6 received more than half of the possible vote. Blocks 1,5, and 7, however, received 
less than half of the vote, with more students rating them as being not helpful than as being very helpful. $20 \%$ of the subjects felt Blocks 1 and 5 were not helpful, and 25\% felt Block 7 was not helpful. This data is contradicted, however, by answers given concerning which step was viewed as being least helpful (question 16). For that rating, $36.8 \%$ of the subjects rated Block 1 as least helpful and only $14 \%$ rated Block 7 as being least helpful.

\section{Summary}

In analyzing the data to ascertain which of the steps in the Seven Building Blocks students perceive to be helpful, descriptive statistics were utilized. It was found that Building Block 4, "Establish Your Priorities," was identified as the most helpful by $47.5 \%$ of the subjects. It received a percentage score of $\mathbf{7 4 . 6 \%}$. Block 3, "Set Your Criteria," was perceived as being the second most helpful, gamering $66.1 \%$ of the possible vote for that step. It was followed by Block 6. "Test the Alternatives," with 55.8\% and Block 2, "State Your Purpose," with 55.6\%. Block 5, "Search for Solutions," and Block 7, "Troubleshoot Your Decision," tied for fifth place with scores of $48.3 \%$. "Smoke Out the Issues," the first Building Block, was seen as the least helpful of all by $36.8 \%$ of the subjects, and received only $45 \%$ of the possible vote for that step.

Though each of the Building Blocks is an integral part of Arnold's decision-making strategy, it is true that some of the steps contain more of the heart of the strategy than others. These steps are Blocks 3, 4. and 6 , which are also the steps identified by students as being the most helpful. They are also the steps requiring the most effort from the decision maker. Blocks 1, 2, and 7 are shorter, and therefore may have been viewed as being less important. Arnold feels they are essential to the whole process, however. Building Block 5, "Search for Solutions," was viewed as not highly helpful. This could well have been due to the nature of the instructional format used. Since this step requires the 
decision maker to search for relevant information and brainstorm possible alternatives, it is a step which cannot be covered well in a short class or seminar setting. Without Block 5, however, a good solution would not likely be attained.

\section{OTHER INTERESTING FINDINGS}

\section{Educational Level and Spontaneous and Systematic Dimensions}

This research has shown statistically significant associations between attitude scores regarding the Seven Building Blocks and educational level, as well as between attitude and the spontaneous and systematic dimensions of decision-making styles. The possibility of an association between educational level and these decision-making dimensions was, therefore, analyzed by means of a chi square test of independence. The results of this test were statistically significant at the .05 level ( $p=.03$ ) with one degree of freedom and a value of 4.759 , as can be observed in Table XV.

Discussion: The results of this test show a definite association between educational level and the spontaneous and systematic dimensions of decision-making style. This finding was unanticipated, as no discussion of such a possibility was mentioned in reviewing the literature regarding decision-making style.

Of the subjects who participated in this study, 29 were high school students and 33 were college students. $34.48 \%$ of the high school students preferred to gather information in a spontaneous manner, compared with only $15.15 \%$ of the college students. $65.52 \%$ of the high school students had systematic decision-making styles and $84.85 \%$ of the college students were systematic. Since these results are significantly different than could be expected by chance, it appears that 
college experience may have an effect upon the way in which students gather data.

TABLE XV

\begin{abstract}
ASSOCLATION OF EDUCATIONAL LEVEL WITH SPONTANEOUS AND STSTEMATIC DECISION-MAKING DIMENSIONS
\end{abstract}

\begin{tabular}{lccc}
\hline & \multicolumn{3}{c}{ Educational Level (High School and College) } \\
Dimensions & High School & College & Total \\
\hline Spontaneous & 10 & 5 & 15 \\
Systematic & 19 & 28 & 57 \\
\hline \hline Total & 29 & 33 & 62 \\
\hline
\end{tabular}

Chi square $=4.759, \mathrm{df}=1, \mathrm{p}=0.03$

This finding may help to explain the reason there is an association between educational level and attitude toward the Seven Building Blocks. Since this strategy involves a fair amount of systematic information gathering and analysis, and since a larger percentage of college students than high school students gather data in a systematic manner, it is not surprising that those with at least two years of college show significantly higher attitudes toward the Seven Building Blocks.

\title{
Decision-Making Style and Gender
}

In the course of this investigation, the association between decision-making style and gender was analyzed by means of chi square tests. The results for the spontaneous and systematic dimensions were not statistically significant, as can be seen in Table XVI. The results for 
the internal and external dimensions, however, were statistically significant at the .05 level $(p=0.001)$. Table XVII shows those results.

TABLE XVI

ASSOCIATION OF SPONTANEOUS AND STSTEMATIC DECISION-MAKING DIMENSIONS WITH GENDER

\begin{tabular}{lcccc}
\hline Dimensions & Female & Gender & Male & Total \\
\hline Spontaneous & 8 & 7 & 15 \\
Systematic & 27 & 20 & 47 \\
\hline \hline Total & 35 & 27 & 62 \\
\hline
\end{tabular}

Chi square $=0.078, \mathrm{df}=1, \mathrm{p}=0.780$

TABLE XVII

ASSOCLATION OF INTERNAL AND EXTERNAL DECISIONMAKING DIMENSIONS WITH GENDER

\begin{tabular}{lcccc}
\hline Dimensions & Female & Gender & Male & Total \\
\hline Internal & 8 & 17 & 25 \\
External & 27 & 10 & 37 \\
\hline \hline Total & 35 & 27 & 62 \\
\hline
\end{tabular}

Chi square $=10.188, \mathrm{df}=1, \mathrm{p}=0.001$ 
Discussion: Approximately one-fourth of the men (25.9\%) and one-fourth of the women (22.9\%) were spontaneous analyzers, while the other three-fourths were systematics. This showed a larger percentage of spontaneous analyzers than was found by Coscarelli (1983) in his research. His studies showed only 10 to $20 \%$ of the population to be spontaneous.

Coscarelli's studies showed a higher percentage of both men and women to be internal processors than external processors. This study's finding that $63 \%$ of the men were internals is in keeping with Coscarelli's results. The finding that $77.1 \%$ of the women were externals, however, is the reverse of what would have been expected. It is an interesting result, but one which would require further research to ascertain the reasons and ramifications for the finding.

\section{Summary}

The analysis of the data regarding educational level and decisionmaking style has shown a definite association between the two. It was found that a larger percentage of high school students have spontaneous decision-making styles (34.48\%) than college students (15.15\%). Therefore, it also follows that a larger percentage of college students are systematic information gatherers than is true of high school students.

No difference was seen between men and women based on the spontaneous and systematic dimensions of decision making. A statistically significant difference was found based on the internal and external dimensions, however. This investigation showed that, for this sample population, a larger percentage of women were external processors and a larger percentage of men were internal processors.

Chapter IV has presented the findings of this investigation regarding the association between student attitude toward the Seven Building Blocks and decision-making style; the association between attitude and age, gender, educational level, life responsibility status, the 
importance attached to being a good decision maker, and the type of decision situation under consideration; student perception of the helpfulness of the various Building Blocks; and interesting findings concerning associations observed in this study between educational level and the spontaneous and systematic decision-making dimensions and the association between decision-making style and gender.

The implications which this study has for the field of education, the applications of the findings which might be made, an overview of the conclusions, and recommendations for implementation and further research are presented in chapter $\mathrm{V}$. 


\section{CHAPTER V}

\section{CONCLUSIONS AND RECOMMENDATIONS}

This chapter is presented in the following format:

1. A summary of the research.

2. Implications which this study has for the field of education.

3. Applications suggested by this research.

4. Selected findings and conclusions of this investigation.

5. Recommendations for the implementation of the findings and for further research.

\section{SUMMARY}

The purpose of this study was to learn more about the attitudes of traditional college-age students toward Arnold's (1978) Seven Building Blocks decision-making strategy, and to seek a pattern which might indicate that students who find the strategy appealing tend to have a particular style or styles of decision making and/or a particular combination of personal characteristics.

Teaching effective decision-making skills is one objective of the overall goals of educational programs. Since decision making is a necessary ingredient in student counseling and advising, it is a skill 
which can logically be taught within the framework of student services programs.

The large number of students being served by postsecondary educational institutions means that educational advising and counseling usually consist of brief encounters between students and their faculty advisers or counselors. Most schools cannot afford to greatly increase their personnel resources in order to expand their services, and therefore need to make the most of the resources they do have. A repertoire of useful tools and strategies to aid in providing services and a means of appropriately matching these tools to individual students could enable existing personnel to serve these students more effectively.

This study looked at one decision-making strategy, the Seven Building Blocks, and sought to ascertain its appeal to traditional collegeage students. Associational patterns were sought between student attitude toward this strategy and a variety of student characteristics, including decision-making style, age, gender, educational level, and liferelated data.

\section{Conclusions of the Review of Literature}

A review of the literature showed a good deal of research and writing concerning traditional college-age students, learning style theory, formal decision theory, and decision-making principles and processes. Two well-delineated decision-making strategies appropriate for teaching students good decision-making skills were found. Studies of prior decision-making courses revealed the effectiveness of teaching decision-making skills in a classroom context.

The review of the literature revealed that what is lacking in the area of decision-making investigation is research regarding the use of specific step-by-step guides for decision making which counselors, advisers, and teachers could utilize in teaching students good decisionmaking skills, and which students could use effectively in making 
decisions. Also lacking in the literature was a means of identifying those students who would be likely to respond positively to such a decisionmaking method. This study sought to provide information which can help to fill this gap in the literature.

\section{Research Questions Investigated}

This investigation was conducted with the following research questions in mind:

1. Do the Seven Building Blocks appeal equally to traditional collegeage students with varying decision-making styles? If not, is there a pattern which might indicate that students with a particular decision- making style find this strategy more or less appealing?

2. Is there an association between student attitude toward the Seven Building Blocks and age, gender, educational level, life responsibility status, attitude regarding decision making, and/or type of decision made using the strategy?

3. Which of the steps in the Seven Building Blocks do students perceive to be helpful?

The following student characteristics were the independent variables in this study:

1. Decision-making styles of the subjects;

2. Age of the subjects;

3. Gender of the subjects;

4. Family responsibility status of the subjects;

5. Importance attached by the subjects to being a good decision maker; and 
6. Type of decision situation dealt with by the subjects.

The dependent variable in this investigation was student attitude toward Arnold's Seven Building Blocks decision-making strategy. An attitude score was constructed from student responses to two questions regarding the way the subjects felt toward the strategy and the process of using it to make a decision. Attitude scores were classified as being low, medium, or high.

\section{Procedures Followed}

Data collected included student decision-making styles as determined by the Decision Making Inventory (Johnson, Coscarelli, and Johnson, 1983), age, gender, educational level, level of independence and family responsibility, work situation, attitude regarding decision making, type of decision situation dealt with using Arnold's strategy, and student attitude regarding the strategy.

The Decision Making Inventory was administered to identify student decision-making styles. A front end decision-making questionnaire obtained demographic data and information regarding student decision-making attitudes and abilities. A 10-page handout was utilized in teaching students how to use the Seven Building Blocks decision-making strategy and guiding them through the process in making a decision of their choice. A response questionnaire was given following this instruction to elicit feedback regarding students' attitudes toward the Seven Building Blocks. The sample population consisted of 62 traditional college-age students currently enrolled in one Oregon high school and three Oregon colleges. 


\section{IMPLICATIONS}

\section{Contribution to the Field of Education}

Information obtained from this study can assist educational counselors, advisors, and teachers in better understanding student attitudes toward decision making in general, and in predicting which students are most likely to respond positively to learning and using a decision-making strategy such as the Seven Building Blocks.

This investigation has shown that traditional college-age students are indeed in the midst of making decisions, many of which are fairly major. It was observed that $\mathbf{8 1 . 9 \%}$ of the students surveyed in this study had either medium or high attitude scores regarding the Seven Building Blocks decision-making strategy. Thus, it would appear that this strategy is a tool which can be effectively used with college students.

Some predictor variables were identified by this study as being characteristics of students who are likely to respond positively to the use of the Seven Building Blocks. These are characteristics which can assist student services personnel and teachers in knowing which students will benefit the most from this strategy. These characteristics include spontaneous decision-making styles, a high level of importance attached to being a good decision maker, and at least two years of college experience. Each of these characteristics will be discussed in the following paragraphs.

Students with systematic, rather than spontaneous, decisionmaking styles, as identified by the administration of the Decision Making Inventory (Johnson, Coscarelli, and Johnson, 1983), are far more likely to have a positive attitude toward the Seven Building Blocks. Since the DMI is quickly administered and scored (it can even be self-scored) and is inexpensive, this predictor variable can easily be used for a large number of the students served by student services programs. 
Students who attach a high level of importance to being a good decision maker are far more likely to have high attitude scores toward the Seven Building Blocks than are students who value decision making at a lower level. This would probably also be true of any decision-making strategy students are shown.

The Seven Building Blocks strategy was shown in this study to be appropriate for students of varying ages, as well as for both women and men. It appears to be appropriate for a wide variety of decision-making situations, though some of the students surveyed felt it would be most helpful for "big" decisions.

Educational level has a great deal of effect upon the attitudes of students toward this decision-making strategy. Those students with little or no college experience reported far lower attitude scores than did the students who had completed at least two years of college. Thus. it may be most appropriate to offer courses and seminars delineating this strategy primarily to students with at least one or two years of college.

It is unclear from this study exactly what there is about educational level which affects student attitudes toward the Seven Building Blocks. That this is not merely an age-related developmental issue seems clear from the fact that chi square tests looking at the association between age and attitude toward the strategy were not statistically significant, while those tests which looked at the association between educational level and attitude were statistically significant. Perhaps greater emphasis is placed upon analytical skills and thinking in college than is the case in high school. The difference between educational levels could also relate to the fact that younger students perceive themselves to have fewer major decisions to make than do those who are nearing the end of their college career. Underclass college students have a large number of required courses to take, while upperclass students are faced with more electives, a need to commit to a major. and an impending decision regarding what to do vocationally 
once college is finished. There may also be a socialization issue at play in this phenomenon. In our society, older students are expected to be making more important decisions regarding careers, marriage, family issues, and finances than are younger students. Older students are likely to be more aware of the seriousness of the decisions which need to be made than are students with less experience. Thus, the issue appears to be rather complex, and probably involves much more than having merely lived through at least two years of college courses.

In rating the helpfulness of the various steps in the Seven Building Blocks, students showed definite preferences for some of the steps over others. All of the steps were seen as being at least somewhat helpful, however, and since each step builds on the previous one, it appears that the use of the strategy in its entirety is highly appropriate for college students. An abbreviated form, encompassing only the first three steps, could also be taught for use in making minor decisions.

An association was observed between educational level and the spontaneous and systematic dimensions of decision-making styles. The percentage of high school students who gather information in a spontaneous manner was more than twice as high as that of spontaneous college students. This would seen to indicate that a much higher number of high school students (more than one-third of them) would not be able to see the validity of using a systematic, analytical decisionmaking strategy such as the Seven Building Blocks. Because of this finding, the use of this strategy is not recommended with high school students.

The students involved in this investigation used the Seven Building Blocks to work on a broad range of decision-making situations. Students who found the strategy to be the most helpful seemed to feel that the decisions on which they were working were important. These decisions included educational goals, career plans, marriage, personal decisions, religious issues, and financial decisions. Many of the students who felt this strategy was too long and boring said it would be more 
appropriate for "big" decisions, but didn't think their decisions fell in that category. Their decisions, however, included most of the same categorles already mentioned. Perhaps they were less ready at the time of the investigation to actually decide on an alternative and proceed with the implementation of their decision. Thus, it appears that this decision-making strategy can work effectively for any number of decision situations. Individual readiness to investigate decision alternatives and commit to one solution may be more crucial to students' attitudes toward the Seven Building Blocks than are the types of decisions being considered.

\section{Recommendations for Further Study}

It is recommended that further research seek corroboration of the predictor variables identified in this study. Studies should involve sample populations from other geographic areas and cultural milleus, and should include non-traditional students as well as those of traditional college-age.

Further studies should be done regarding the construction of attitude scores. While it was felt that the attitude scores constructed for this study were helpful in carrying out this research, it would be useful to have a well-defined standardized method for identifying attitude scores.

Many of the students who participated in this study commented on the usefulness of the Seven Building Blocks decision-making strategy for making "big" decisions. Further study should be done with college students to better identify how they differentiate between big and little. or between major and minor, decisions. Further research should also be done using the strategy in individual counseling situations to ascertain whether it is more or less effective than the class format used in this study. 
Some interesting findings were reported in this study concerning the possible association between attitude score and living situation, and between attitude score and work situation. It is possible that these two variables may be indicators of a higher level of responsibility; however, the number of subjects in this study who were living independently and/or who were working full time was too small to achieve statistically significant results in the chi square tests run. Therefore, further research is recommended which would involve a sample including more subjects who live independently and who work full time. This would probably necessitate including students older than the traditional college age. Further study should also be done to ascertain the possible association between responsibility level, living situation, work situation, and other variables.

Many students, especially those with lower educational levels, felt that the Seven Building Blocks strategy was too long and should be made shorter for them to feel comfortable using it. It is recommended that further research be done to take the basic principles of this strategy and create a shortened version which can be applied to those students who feel overwhelmed by a 10-page decision-making handout. This shorter version might prove to be effective for high school students and lowerlevel college students, and may well prove popular with upperclass collegians as well.

Finally, further research is needed to determine the effectiveness of this strategy in individual and group counseling situations. A shortened version of the Seven Building Blocks would likely be easier to use in these settings. This would seem to be an appropriate use of the strategy for students with two or more years of college. The appropriateness of using the shortened version in group settings with high school and beginning college students would need to be investigated further, especially in regard to the way in which peer pressure may impact group dynamics in a group decision-making situation. 


\section{APPLICATIONS}

The Seven Building Blocks decision-making strategy was taught in this study in group settings using lecture format and worksheet handouts. Since more than four-fifths of the participants in the study reported either medium or high attitude scores regarding the strategy. this proved to be an acceptable manner of utilizing the strategy. It is this researcher's studied opinion that the strategy could be at least as useful in individual counseling situations, providing the counselor is familiar with the strategy and feels comfortable using it. It is also this researcher's opinion that the strategy is not highly appropriate for use at the high school level, since such a large percentage of high school students achieved low attitude scores regarding the strategy.

This strategy can be incorporated by college and university student services personnel and teachers in seminars or courses offered to assist students in learning good decision-making skills, in making educational and career decisions, and in dealing with other life decision situations. In course settings, the strategy can be used exactly as it was used in this study by following the lecture notes found in Appendix $E$ and guiding students through the strategy by means of the 10-page handout in Appendix D. These materials should be adapted to fit the individual instructor, the students, and the situation.

The Seven Building Blocks can also be incorporated by college counselors and advisors in individual and group counseling situations. This can be done by leading students through the strategy verbally, or by giving them copies of the handout (Appendix D) and guiding them through the various steps. Group counseling settings would enable students to help each other think through the issues and values involved in their decisions, and to brainstorm creative solutions for their situations. More private decisions can be dealt with by incorporating the techniques of the Seven Building Blocks in individual counseling sessions. This will probably be most effectively done by asking clients 
the questions verbally, rather than by using the handout. Each counselor or adviser should adapt the techniques in a manner which will be appropriate to each individual client and situation.

Counselors, teachers, and advisers who plan to use this strategy should obtain copies of Arnold's (1978) book, The Art of Decision Making. Copies of the book could also be available to students interested in the strategy for further reference beyond that provided in the handout. Handouts detailing the strategy could be made available to students through the student services department or through an individual teacher or counselor.

The Decision Making Inventory (Johnson, Coscarelli, and Johnson. 1983) could be administered to students participating in decision-making courses, students involved in individual or group counseling, and students utilizing student services resources and interested in finding out more about their own decision-making styles. The inventory can be administered to students by student services personnel in order to understand how the students prefer to gather and process information. This information can, in turn, be used to determine the likelihood of positive student response to the use of the Seven Building Blocks.

\section{CONCLUSTONS}

\section{Selected Findings}

Statistical analyses involving chi square tests of independence implemented by contingency tables and descriptive statistics resulted in a number of findings.

1. The Seven Building Blocks decision-making strategy appeals to individuals who gather information in a 
systematic manner more than to those who gather it spontaneously $(\mathrm{p}=0.001)$.

2. There is no significant difference between the attitude scores toward the Seven Building Blocks of individuals who analyze information internally and those who are external analyzers ( $p=0.883$ ).

3. There is no significant difference between the attitude scores toward the Seven Building Blocks of students of varying ages $(p=0.346)$.

4. There is no significant difference between the attitude scores toward the Seven Building Blocks of men and of women ( $p=0.942)$.

5. Students who have completed two or more years of college have significantly higher attitude scores regarding the Seven Building Blocks than do students who have completed less than two years of college ( $p=0.007)$.

6. There is no significant difference between the attitude scores toward the Seven Building Blocks of students with greater life responsibilities and those with fewer life responsibilities.

7. A greater level of appeal for the Seven Building Blocks is shown by students who attach a high level of importance to being good decision makers than by students who value decision making at a lower level (p = 0.001).

8. There is no significant difference between the attitude scores toward the Seven Building Blocks of students grappling with pressing decision situations and students without pressing decision situations. 
9. Building Block 4, "Establish Your Priorities," is seen by students as being the most helpful step in the Seven Building Blocks. Blocks 2, 3, and 6 were also perceived as being quite helpful. Blocks 5 and 7 were seen as being less helpful. Block 1 was seen as the least helpful.

\section{Conclusions Related to the Research Questions}

These conclusions address the research questions posed by this study by interpreting the selected findings resulting from the research. The following discussion is presented in relation to the three major questions.

1. Do the Seven Building Blocks appeal equally to traditional collegeage students with varying decision-making styles? If not, is there a pattern which might indicate that students with a particular decision- making style find this strategy more or less appealing?

This research showed that the Seven Building Blocks decisionmaking strategy does not appeal equally to traditional college-age students with varying decision-making styles. A pattern was seen which indicates that students who gather data in a systematic manner, regardless of the way in which they process the information, achieve significantly higher attitude scores toward the strategy than do students who gather data in a spontaneous manner. No statistically significant difference in attitude was revealed between students who analyze data internally and those who analyze it externally. Therefore, students with systematic internal and systematic external decision-making styles find the Seven Building Blocks more appealing than do students with spontaneous internal and spontaneous external styles. 
2. Is there an association between student attitude toward the Seven Building Blocks and age, gender, educational level, life responsibility status, attitude regarding decision making, and/or type of decision made using the strategy?

Associations exist between student attitude toward the Seven Building Blocks and educational level and attitude regarding decision making. Students who have at least two years of college experience have higher attitude scores than do students with less college experience. Students with high or very high attitudes regarding the importance of being a good decision maker have higher attitude scores toward the strategy than do students who place less importance on being good decision makers.

No statistically significant association was found in this investigation between attitude scores toward the Seven Building Blocks and age, gender, life responsibility status, or type of decision situation dealt with by students learning to use this strategy.

\section{Which of the steps in the Seven Building Blocks do students perceive to be helpful?}

Building Block 4, "Establish Your Priorities," is perceived by students as being the most helpful of the Seven Building Blocks. Block 3. "Set Your Criteria," Block 6. "Test the Alternatives," and Block 2 , "State Your Purpose," are also perceived as being quite helpful. Block 5 , "Search for Solutions," and Block 7. "Troubleshoot Your Decision," are perceived as being less helpful. Block 1, "Smoke Out the Issues," is perceived as being the least helpful of the seven steps.

Overall, the majority of students found the Seven Building Blocks to be at least somewhat helpful. Many felt the strategy could be improved by making it shorter. Many students with less educational 
experience felt that the strategy was rather repetitious and boring. Students with more college experience tended to like the strategy as it stands, though many admitted they would not likely use all the steps for most decisions which they have to make. (See Appendix $\mathrm{H}$ for verbatim student comments regarding their feelings about the strategy.)

\section{RECOMMENDATIONS}

\section{Recommendations for the Implementation of the Findings}

In recent years, much attention has been focused on providing effective and comprehensive student services programs. The educational community has increasingly seen the need to prepare students to think on their own and has been concerned with the development of courses aimed at helping students improve their critical thinking skills, including those necessary for effective decision making.

The large number of students served by students services programs, combined with limited financial and personnel resources, means that educational institutions need to make the most of the resources available to them. This study investigated one useful tool, the Seven Building Blocks decision-making strategy, and sought a means of appropriately matching this tool with students who would find this strategy appealing and who could benefit from the use of such a tool.

On the basis of the review of literature and the results of this investigation, the following recommendations are made with a view to improving the services offered to students in the area of decisionmaking skill training.

1. The Seven Building Blocks decision-making strategy should be incorporated by college and university student services personnel in seminars and courses offered to assist students in learning good 
decision-making skills, in making educational and career decision, and in dealing with other life decision situations.

2. A shortened version of the Seven Building Blocks, which would have greater appeal for students with less than two years of college experience, should be developed and tested.

3. The Seven Building Blocks should be utilized by postsecondary counselors and advisors in individual and group counseling situations. This should be done by using the principles of the strategy in counseling sessions or by facilitating student decision making by helping students work through the process with the aid of a worksheet such as that used for this investigation (see handout in Appendix D).

4. Arnold's (1978) book, The Art of Decision Making. should be made available to student services personnel who could use it in their contact with students. Copies of the book should also be available to other faculty members and to students interested in learning good decision-making techniques.

5. Handouts detailing the Seven Building Blocks should be made available to students through the student services department or through individual teachers and counselors.

6. The Decision Making Inventory (Johnson, Coscarelli, and Johnson, 1983) should be administered to students who participate in decision-making courses or seminars, to students who are involved in individual or group counseling, and to students who make use of student services resources. The results of the inventory should be explained to students to enable them to better understand how they make decisions. The information regarding student decision-making style should also be utilized by student services personnel to help identify those students who would most likely enjoy and benefit from using the Seven Building Blocks strategy. 


\section{Recommendations for Further Research}

The results of this study provided a number of findings regarding the investigation's research questions. They also raised a number of new questions. Based on the findings and conclusions of this study, a number of recommendations for further research are presented.

1. Further research should seek corroboration of the predictor variables identified in this study, as well as seek other predictor variables which might also be useful in determining those students who are most likely to benefit from the use of the Seven Building Blocks decision-making strategy.

2. Further studies should be conducted using sample populations from other geographic areas and cultural milieus, in order to test the generalizability of the study's findings.

3. This study should be replicated for students who are not traditional college age, in order to ascertain whether or not the results obtained from studying 16 - to 23-year olds is also valid for older students.

4. Further studies should be done to better define a method for constructing reliable attitude scores.

5. Since many of the students who participated in this study perceived that the use of the Seven Building Blocks would be most appropriate for "big" decisions, it is recommended that further research be done to better identify how college students differentiate between major and minor decisions, and whether there is a difference in their attitude toward using the decision-making strategy based on this differentiation.

6. Since interesting findings were reported in this study concerning the possible association between attitude score toward the Seven Building Blocks and living independently, and between attitude and working full time. further studies should be performed which 
involve a larger sample of students who live independently and who work full time to ascertain whether or not an association does exist.

7. It is recommended that further research be done to take the basic principles of the Seven Building Blocks decision-making strategy and create a shortened version which could be applied to those students who feel that the strategy in its entirety is too long and too time consuming for them to feel comfortable using it. The current study should then be replicated using the shortened version to ascertain whether or not the same predictor variables would be useful in identifying students who would benefit from that version.

8. Further investigation of the association between educational level and the spontaneous and systematic dimensions of decisionmaking style should be done to verify the findings of this study that more than one-third of the high school students gather information in a spontaneous manner while only $15 \%$ of college students gather information spontaneously. The effect which the university setting may have upon these findings should be investigated.

9. Further research should be done to develop a shortened version of the Seven Building Blocks which would appeal to students who have completed less than two years of college. This version should then be studied to determine its appropriateness for students of varying educational levels, ages, geographic locations, cultures, and life responsibility status. 


\section{REFTRENCES}

Anderson, Barry F. 1980. The Complete Thinker. Englewood Cliffs, N.J.: Prentice-Hall, Inc.

Arkes, Hal R. and Hammond, Kenneth R., Eds. 1986. Judgment and Decision Making: An Interdisciplinary Reader. Cambridge: Cambridge University Press.

Arnold, John D. 1978. The Art of Decision Making. New York: Amacom.

Arnold, John D. \& Tompkins, Bert L. 1982. How to Make the Right Decisions. Milford, MI: Mott Media, Inc.

Arnold, John D. 1984. Trading Up: A Career Guide. Garden City, N.Y.: Anchor Press/Doubleday.

Astin. Alexander W. 1985. Achieving Educational Excellence. San Francisco: Jossey-Bass Publishers.

Barr, Margaret J. and Keating, Lou A. 1985. "Introduction: Elements of Program Development." In Developing Effective Student Services Programs, edited by Margaret J. Barr, Lou A. Keating, and Associates. San Francisco: Jossey-Bass Publishers, 1-12.

Behn, Robert D. \& Vaupel, James W. 1982. Quick Analysis for Busy Decision Makers. New York: Basic Books, Inc., Publishers.

Berger, Dale E.; Pezdek, Kathy; and Banks, William P., Eds. 1987. Applications of Cognitive Psychology: Problem Solving, Education, and Computing. Hillsdale, N.J.: Lawrence Erlbaum Associates, Publishers.

Bergmann. Sherrel and Rudman, Gerald J. 1985. Decision-Making Skills for Middle School Students. Washington, D.C.: National Education Association.

Beyer, Barry K. 1988. "Developing a Scope and Sequence for Thinking Skills Instruction." In Educational Leadership. April 1988, v. 45, 26-30. 
Cassidy, Edward W. and Kurfman, Dana G. 1977. "Decision Making as Purpose and Process." In Developing Decision-Making Skills, edited by Dana G. Kurfman. Washington, D.C.: National Council for the Social Studies, 1-26.

Cochran, Donald J.; Hetherington, Cheryl; \& Strand, Kenneth H. 1980. "Career Choice Class: Caviar or Caveat." In Journal of College Student Personnel. September, 1980, 402-406.

Connolly, Terry. 1982. "On Taking Action Seriously: Cognitive Fixation in Behavioral Decision Theory." In Decision making: An Interdisciplinary Inquiry, edited by Gerardo $\mathbf{R}$. Ungson and Daniel $\mathbf{N}$ Braunstein. Boston, MA: Kent Publishing Co.

Coscarelli, William C. 1983. Manual for The Decision Making Inventory. Columbus, Ohio: Marathon Consulting and Press.

Dudley, Gordon A. and Tiedeman, David V. 1977. Career Development: Exploration and Commitment. Muncie, IN: Accelerated Development Inc.

Ebbesen, Ebbe B. \& Konecni, Vladimir J. 1980. "On External Validity of Decision-making Research: What Do we Know about Decisions in the Real World?" In Cognitive Processes in Choice and Decision Behavior, edited by Thomas S. Wallsten. Hillsdale, N.J.: Lawrence Erlbaum Associates, Publishers.

Einhorn, Hillel J. \& Hogarth, Robin M. 1982. "Behavioral Decision Theory: Processes of Judgment and Choice." In Decision making: An interdisciplinary inquiry, edited by Gerardo $\mathbf{R}$. Ungson and Daniel N. Braunstein. Boston, MA: Kent Publishing Co.

Elias, Maurice J. and Clabby, John F. 1988. "Teaching Social Decision Making." Educational Leadership. March 1988, 45, 52-55.

Evans, John R. \& Rector, Alice P. 1978. "Evaluation of a College Course in Career Decision Making." In Journal of College Student Personnel, March 1978, 163-168.

Gelatt, H. B. 1962. "Decision-making: A Conceptual Frame of Reference for Counseling." In Journal of Counseling Psychology, 9, 240-245.

Gordon, Virginia N. 1984. The Undecided College Student: An Academic and Career Advising Challenge. Springfield, IL: Charles C. Thomas, Publisher.

Gordon, Virginia N.: Coscarelli, William C.: and Sears, Susan J. 1986. "Comparative Assessments of Individual Differences in Learning and Career Decision Making." In Journal of College Student Personnel, 27, 233-242. 
Halpern, Diane F. 1987. "Analogies as a Critical Thinking Skill." In Applications of Cognitive Psychology: Problem Solving, Education, and Computing, edited by Dale E. Berger; Kathy Pezdek; and William P. Banks. Hillsdale, N.J.: Lawrence Erlbaum Associates, Publishers, 75-86.

Healy, Charles C. 1982. Career Development: Counseling Through the Life Stages. Boston: Allyn and Bacon, Inc.

Heirs, Ben. 1987. The Professional Decision-Thinker: America's New Management and Education Priority. New York: Dodd, Mead \& Company.

Heppner, P. Paul \& Krieshok, Thomas S. 1983. "An Applied Investigation of Problem-solving Appraisal, Vocational Identity and Career Service Requests, Utilization, and Subsequent Evaluations." In The Vocational Guidance Quarterly, 32, 240-249.

Hogarth, Robin M. 1980. Judgement and Choice. Chichester: John Wiley \& Sons.

Holland, John L. \& Holland, Joan E. 1977. "Vocational Indecision: More Evidence and Speculation." In Journal of Counseling Psychology, 24, 404-414.

Horan, John J. 1979. Counseling for Effective Decision Making. North Scituate, MA: Duxbury Press.

Hurst, James C. and Jacobson, Judith K. 1985. "Theories Underlying Students' Needs for Programs." In Developing Effective Student Services Programs, edited by Margaret J. Barr, Lou A. Keating, and Associates. San Francisco: Jossey-Bass Publishers, 113-136.

Inhelder, B., and Piaget, Jean. 1958. The Growth of Logical Thinking from Childhood to Adolescence. New York: Basic Books.

Jacobi, Maryann; Astin, Alexander; and Ayala, Frank, Jr. 1987. College Student Outcomes Assessment: A Talent Development Perspective. ASHE-ERICHigher Education Report No. 7. Washington, D.C.: Association for the Study of Higher Education.

Janis, Irving L. 1982a. "Problems of Short-term Counseling." InCounseling on personal decisions: Theory and research on short-term helping relationships, edited by Irving L. Janis. New Haven and London: Yale University Press.

Janis, Irving L. 1982b. Stress, Attitudes, and Decisions: Selected Papers. New York: Praeger Publications. 
Janis, Irving L. and Mann, Leon. 1977. Decision Making: A Psychological Analysis of Conflict, Choice, and Commitment. New York: The Free Press.

Janis, Irving L. and Mann, Leon. 1982. "A Theoretical Framework for Decision Counseling." In Counseling on personal decisions: Theory and research on short-term helping relationships, edited by Irving L. Janis. New Haven and London: Yale University Press.

Johnson, Richard H. 1978. "Individual Styles of Decision Making: A Theoretical Model for Counseling." In Personnel and Guidance Joumal, 56, 530-536.

Johnson, Richard H.; Coscarelli, William C.; and Johnson, J. 1983. The Decision Making Inventory. Columbus, $\mathrm{OH}$ : Marathon Consulting and Press.

Keefe, James W. 1988. "Development of the NASSP Learning Style Profile." In Profiling and Utilizing Learning Style, edited by James W. Keefe. Reston, VA: National Association of Secondary School Principals, 1-22.

Keeney, Ralph L. 1982. "Decision Analysis: An Overview," Operations Research, Vol. 30, No. 5, Sept.-Oct. 1982, 803-838.

Letteri, Charles A. 1988. "The NASSP Learning Style Profile and Cognitive Processing." In Profiling and Utilizing Learning Style. edited by James W. Keefe. Reston, VA: National Association of Secondary School Principals, 23-34.

Levine, Arthur. 1981. "The College Student: A Changing Constituency." In Higher Education in American Society, edited by Philip G. Altbach and Robert O. Berdahl. Buffalo, N.Y.: Prometheus Books.

Mackes, Marilyn \& Beidler, Peter. 1983. "Effective Student Development: Three Principles in Action." In Journal of College Placement, 43, 40-44.

McMinn, Gordon N. \& Libby, Larry. 1980. Taking Charge: The Dynamics of Personal Decision Making and Self-management. Denver, CO: Accent B/P Publications, Inc.

Meyers, Chet. 1987. Teaching Students to Think Critically. San Francisco: Jossey-Bass Publishers.

Mitchell, James V. Jr. 1985. The Ninth Mental Measurements Yearbook. Vol. I. The Buros Institute of Mental Measurements, Lincoln, NB: The University of Nebraska Press. 
Moshman, David and Neimark, Edith. 1982. "Four Aspects of Adolescent Cognitive Development." In Review of Human Development, edited by Tiffany $M$. Field and others. New York: John Wiley.

Nummedal, Susan G. 1987. "Developing Reasoning Skills in College Students." In Applications of Cognitive Psychology: Problem Solving, Education, and Computing, edited by Dale E. Berger; Kathy Pezdek; and William P. Banks. Hillsdale, N.J.: Lawrence Erlbaum Associates, Publishers, 87-97.

Osipow. Samuel H. 1983. Theories of Career Development. Englewood Cliffs, N.J.: Prentice-Hall, Inc.

Patterson, Lewis E. \& Eisenberg. Sheldon. 1983. The Counseling Process. Boston: Houghton Mifflin Co.

Payne, John W. 1980. "Information Processing Theory: Some Concepts and Methods Applied to Decision Research." In Cognitive processes in choice and decision behavior, edited by Thomas S. Wallsten. Hillsdale, N.J.: Lawrence Erlbaum Associates, Publishers.

Phillips, Susan D. \& Strohmer, Douglas C. 1982. "Decision Making Style and Vocational Maturity." In Journal of Vocational Behavior, 20. 215-222.

Piaget, Jean. 1985. The Equilibration of Cognitive Structures: The Central Problem of Intellectual Development. Chicago: The University of Chicago Press.

Presseisen, Barbara Z. 1986. Thinking Skills: Research and Practice. Washington, D.C.: National Education Association.

Richmond, P.G. 1970. An Introduction to Piaget. New York: Basic Books.

Rubin, Theodore Isaac, M.D. 1985. Overcoming Indecisiveness: The Eight Stages of Effective Decisionmaking. New York: Harper and Row, Publishers.

Russel, John H. and Sullivan. Thomas. 1979. "Student Acquisition of Career Decision-making Skills as a Result of Faculty Advisor Intervention." Journal of College Student Personnel. July 1979, 291-296.

Simon, Herbert A. 1957. Models of Man. New York: John Wiley.

Simon. Herbert A. 1977. The New Science of Management Decision. rev. ed. Englewood Cliffs, N.J.: Prentice-Hall. 
Slaney, Robert B. 1984. "Relations of Career Indecision to Changes in Expressed Vocational Interests." In Journal of Counseling Psychology. 31, 349-355.

Smith, Robert M. 1982. Learning How to Learn. Chicago, IL: Follett Publishing Company.

Srebalus, David J.; Marinelli, Robert P.; \& Messing, Jeffrey K. 1982. Career Development Concepts and Procedures. Monterey, CA: Brooks/Cole Publishing Company.

Stiggins, Richard J.: Rubel, Evelyn; and Quellmalz, Edys. 1988. Measuring Thinkings Skills in the Classroom. Washington, D.C.: National Education Association.

Super. Donald E. 1983. "Assessment in Career Guidance: Toward Truly Developmental Counseling." In The Personnel and Guidance Journal, 61, 555-562.

Tiedeman, David V. 1972. "Can a Machine Develop a Career? A Structure for the Epigenesis of Self-Realization in Career Development." In Perspectives on Vocational Development, edited by John $M$. Whiteley and Arthur Resnikoff. Washington, D.C.: The American Personnel and Guidance Association.

Tversky, Amos \& Kahneman, Daniel. 1985. "The Framing of Decisions and the Psychology of Choice." In Behavioral decision making, edited by George Wright. New York: Plenum Press.

Tyler, Leona E. 1965. The Psychology of Human Differences. New York: Appleton-Century-Crofts.

Ungson, Gerardo R. \& Braunstein, Daniel N., Eds. 1982. Decision Making: An Interdisciplinary Inquiry. Boston. MA.: Kent Publishing Co.

VanGundy, Arthur B. 1988. Techniques of Structured Problem Solving. New York: Van Nostrand Reinhold Company.

Wales, Charles E.; Nardi, Anne H.; and Stager, Robert A. 1986. "Decision Making: New Paradigm for Education." In Educational Leadership, 43, No. 8 (May 1986), 37-41.

Wallsten, Thomas S., Ed. 1980. Cognitive Processes in Choice and Decision Behavior. Hillsdale, N.J.: Lawrence Erlbaum Associates, Publishers.

Weathersby, Rita Preszler. 1981. "Ego Development." In The Modern American College, edited by Arthur W. Chickering and Associates. San Francisco: Jossey-Bass Publishers. 
Wheeler, Daniel D. \& Janis, Irving L. 1980. A Practical Guide for Making Decisions. New York: The Free Press.

Wright, George. 1984. Behavioral Decision Theory. Beverly Hills, CA: Sage Publications.

Wright, George, Ed. 1985. Behavioral Decision Making. New York: Plenum Press.

Zaccaria, Joseph S. 1970. Theories of Occupational Choice and Vocational Development. Boston: Houghton Mifflin Company.

Zakay, Dan \& Barak, Azy. 1984. "Meaning and Career Decision Making." In Journal of Vocational Behavior, 24, 1-14. 
APPENDIX A

THE DECISION MAKING INVENTORY 


\section{PLEASE NOTE:}

Copyrighted materials in this document have not been filmed at the request of the author. They are available for consultation, however, in the author's university library.

These consist of pages:

101

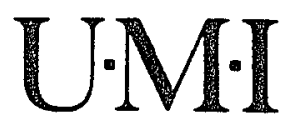


APPENDIX B

THE DECISION MAKING QUESTIONNAIRE 
ID \#

\section{DECISION-MAKING QUESTIONNAIRE}

1. What level of importance do you attach to being a good decision maker? (circle number)
1. VERY LOW
2. LOW
3. FAIR
4. HIGH
5. VERY HIGH

2. How would you rate yourself as a decision maker?
1. POOR
2. FAIR
3. GOOD
4. EXCELLENT

3. Do you feel other people see you as a good decision maker?

1. NO

2. YES

4. Can you accurately describe the strategy you normally use to make decisions?

1. NO, I COULDNT DESCRIBE IT

2. YES, I COULD DESCRIBE IT VAGUELY

3. YES, I COULD DESCRIBE TT QUTTE WEU

5. If your answer to question \#4 was 2 or 3 , please describe your normal decision-making strategy briefly in the space provided below. If you need more room you may use the back of this page. 
6. Which of the following methods of decision making do you prefer?

1. MAKING DECISIONS ON THE BASIS OF WHAT "FEELS RIGHT" (INTUITION)

2. SYSTEMATICALLY COLIECTING AND ANALYZING DATA TO REACH A DECISION

3. AVOIDING MAKING DECISIONS AND HAVING SOMEONE ELSE MAKE THEM FOR

7. What level of satisfaction do you feel about your current decision making techniques? (circle number)

1. VERYLOW

2. LOW

3. FAIR

4. HIGH

5. VERYHIGH

8. What was your age on your last birthday?

9. What is your gender?

1. FEMALE

2. MALE

10. What is your marital status?

1. SINGLE

2. ENGAGED

3. MARRIED

4. SEPARATED

5. DIVORCED

11. Do you have children?

1. NO

2. YES, BUT NOT LIVING WITH ME

3. YES, LIVING WITH ME

12. Which of the following best describes your living situation.

1. LIVING WITH PARENTS OR OTHER RELATIVE

2. LIVING INDEPENDENTLY

3. LIVING WITH A SPOUSE OR PARTNER

13. How many years of college have you completed? 
14. Are you currently working?

1. NO

2. YES, PART TIME

3. YES, FULL TIME

15. Have you chosen a career yet?

1. NO

2. YES 
APPENDIX C

THE RESPONSE TO ARNOLD'S SEVEN BUILDING BLOCKS QUESTIONNAIRE 
ID \#

\section{RESPONSE TO ARNOLD'S SEVEN BUILDING BLOCKS QUESTIONNAIRE}

1. What level of importance do you attach to acquiring good decision-making skills? (circle number)
1. VERY LOW
2. LOW
3. FAIR
4. HIGH
5. VERY HIGH

2. How would you rate the effectiveness of Amold's Seven Building Blocks as a decision-making strategy? (circle number)
1. VERY LOW
2. LOW
3. FAIR
4. HIGH
5. VERY HIGH

3. How would you rate the thoroughness of Arnold's Seven Building Blocks compared with decision-making techniques you have used in the past?

1. LESS THOROUGH

2. ABOUT THE SAME LEVEL OF THOROUGHNESS

3. MORE THOROUGH

4. Which of the following statements best reflects your feelings about the Seven Building Blocks?

1. TOO ANALYTICAL

2. APPROPRIATELY ANALYTICAL

3. NOT ANALYTICAL ENOUGH

5. How did you feel about the Seven Building Blocks when they were first introduced to you?

1. NOT INTERESTED

2. SOMEWHAT INTERESTED

3. VERY INTERESTED 
6. Now that you have used the Seven Building Blocks in working on a decision, what are your feelings about the strategy?

1. NOT ENTHUSIASTIC

2. SOMEWHAT ENTHUSIASTIC

3. VERY ENTHUSIASTIC

7. How satisfied do you feel with the decision you made using the Seven Building Blocks?

1. DISSATISFIED

2. SLIGHTLY DISSATISFIED

3. SOMEWHAT SATISFIED

4. HIGHLY SATISFIED

5. IDONT KNOW YET

6. I HAVEN'T MADE A DECISION YET

8. What kind of decision were you working on using this strategy? (career, marriage, educational, relationship, personal, etc.)

9. How important is this decision to you?

1. NOT VERY IMPORTANT

2. MODERATELY IMPORTANT

3. VERY IMPORTANT

10. Was this a decision which you had already been considering prior to the sessions on the Seven Building Blocks strategy?

1. NO

2. YES

11. What level of stress do you feel about this decision?

1. LOW

2. MEDIUM

3. $\mathrm{HIGH}$

12. Do you feel this exercise played an important part in helping you make this decision?

1. NO

2. YES 
13. How do you feel about the process you went through in making a decision using the Seven Building Blocks?

1. DISSATISFIED

2. SLIGHTLY DISSATISFIED

3. SOMEWHAT SATISFIED

4. HIGHLY SATISFIED

14. How helpful did you feel each of the steps in the Seven Building Blocks was in making a decision? (place a check mark in the appropriate column for each step)

1. SMOKE OUT THE ISSUES .....

2. STATE YOUR PURPOSE ......

3. SET YOUR CRITERIA .........

4. ESTABLISH YOUR PRIORITIES.

5. SEARCH FOR SOLUTIONS ....

6. TEST THE ALTERNATIVES. ....

7. TROUBLESHOOT YOUR DECISION

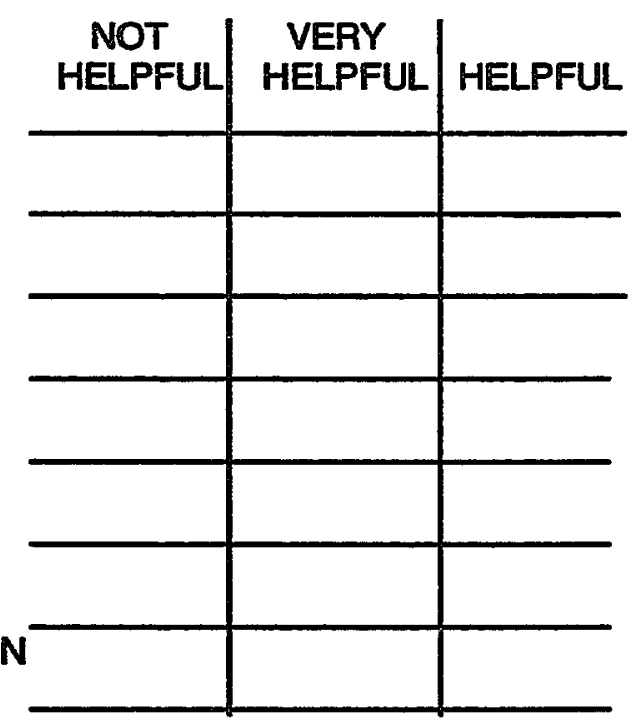

15. Which of the steps in the Seven Building Blocks did you find the most helpful? (circle only one number)

1. SMOKE OUT THE ISSUES

2. STATE YOUR PURPOSE

3. SET YOUR CRITERIA

4. ESTABLISH YOUR PRIORITIES

5. SEARCH FOR SOLUTIONS

6. TEST THE ALTERNATIVES

7. TROUBLESHOOT YOUR DECISION

16. Which of the steps in the Seven Building Blocks did you find the least helpful? (circle only one number)

1. SMOKE OUT THE ISSUES

2. STATE YOUR PURPOSE

3. SET YOUR CRITERIA

4. ESTABLISH YOUR PRIORITIES

5. SEARCH FOR SOLUTIONS

6. TEST THE ALTERNATIVES

7. TROUBLESHOOT YOUR DECISION 
17. Do you feel you will incorporate aspects of the Seven Building Blocks into your decision-making strategy in making future decisions?

1. NO

2. YES

18. If your answer to question 17 was YES, which of the steps in the Seven Building Blocks do you plan to incorporate in further decision making? (circle all numbers that apply)

1. SMOKE OUT THE ISSUES

2. STATE YOUR PURPOSE

3. SET YOUR CRITERIA

4. ESTABLISH YOUR PRIORITIES

5. SEARCH FOR SOLUTIONS

6. TEST THE ALTERNATIVES

7. TROUBLESHOOT YOUR DECISION

19. Describe briefly your reactions to Arnold's Seven Building Blocks.

20. What changes would you like to see made in the Seven Building Blocks? Describe them briefly. 
APPENDIX D

THE SEVEN BUILDING BLOCKS HANDOUT 


\section{PLEASE NOTE:}

Copyrighted materials in this document have not been filmed at the request of the author. They are available for consultation, however, in the author's university library.

\section{These consist of pages:}

112-121

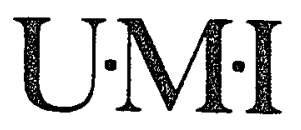


APPENDIX E

LECTURE NOTES FOR TEACHING THE SEVEN BUILDING BLOCKS 
Since most of the students who participated in this study received instruction regarding the Seven Building Blocks in two consecutive class hours, the lecture notes are presented in a two-class format. For those students who participated in the two-hour seminars, these lectures were modified into one lecture and the review at the beginning of the second lecture was deleted.

\section{LECTURE NOTES \#1}

\section{TFE SEVEN BUILDING BLOCKS}

\section{INTRODUCTION (2 min.)}

Do any of you have a hard time making decisions? Do you feel like you're muddling through life without much sense of control?

I'm doing some research in the area of decision making, and would like to teach you a decision-making strategy, and then get your feedback regarding how you liked using the strategy. I hope our time together will benefit all of us. It will help me by furthering my research. It can help you learn a decision-making strategy, apply that strategy to a decision you need to make, and find out what your decision-making style is.

In the time we have to learn about this decision-making strategy, you will have the opportunity to work on a decision which you need to make sometime in the relatively near future. It could be a major decision or a smaller one. Some ideas to consider are career goals, educational plans, finances, a major purchase, ani upcoming event, or a decision regarding a personal relationship. All that is required is that it be a decision which you need to make, so start thinking about what decision you would like to work on.

\section{INFORMED CONSENT FORM ( $3 \mathrm{~min}$.}

First of all, you need to be aware of what this study entails. (Hand out Informed Consent Form." Read through it and discuss it, then have students sign forms and hand them in.)

\section{DECISION MAKING INVENTORY (10 min.)}

(Hand out the Decision Making Inventory. )

This is the Decision Making Inventory, which will be used to identify your decision-making style. Please put your name at the top of the 
inventory. Then use the last 5 digits of your social security number as your ID number, and put that number at the top of this inventory. Take a few minutes to answer all the questions in the inventory to the best of your ability. (Collect inventories when students are finished with them.)

\section{DECISION-MAKING GUESTIONNAIRE (10 min.)}

I would like you to fill out the Decision-Making Questionnaire now, before we begin looking at Amold's decision-making strategy. Please put your 5-digit ID number at the top of the page. (Hand out DecisionMaking Questionnaires. Collect them when students are finished filling them out)

Thank you. Now let's take a look at Arnold's Seven Building Blocks. Please feel free to ask questions or to share appropriate comments as we go along.

THE SEVEN BURLING BLOCKS, INTRODUCTION (2 min.)

(Hand out "The Seven Building Blocks" handout, then read through page 1.)

\section{BUILDING BLOCK 1: SMOKE OUT THE ISSUES (5 min.)}

Have you decided what decision you need to make and would like to work on while learning about this strategy? If not, take a moment and choose one. The ideas I suggested earlier were decisions regarding career goals, educational plans, finances, a major purchase, an upcoming event, or a personal relationship. These are only suggestions. You may use any decision which is currently on your mind.

Now, think about your decision situation. Do you have to make a decision? Why? What will happen if you don't make a decision? Turn to page 2, and we'll look at Building Block 1.

(Read through page 2, and give students time to fill in their answers, then read the top half of page 3 and give time for those answers.) 
BUILDING BLOCK 2: STATE YOUR PURPOSE (5 min.)

It isn't necessarily obvious what your real purpose in this decision situation is. You may need to ask yourself "Why" several times to get to the real purpose. Keep asking yourself if there is something else behind what you have stated so far as being your purpose.

(Guide students through building block 2, at the bottom of page 3.)

BUILDING BLOCK 3: SET YOUR CRITERIA (8 min.)

Building Block 3 asks you to set your criteria by asking yourself what you want to achieve, preserve, and avoid in making this decision. An example of this is the story of a young woman whose co-worker was getting married. The office workers collected $\$ 200$ to buy a wedding gift for their friend. This woman decided to smoke out the issues, state her purpose, and set criteria for her decision situation before going out to buy the gift. Let's look at this example. (Put transparency \#I on overhead and discuss.)

Let's look at another example. This person was looking for work. She decided that her purpose was to "determine the best type of work for me." (Put transparency \#2 on overhead and discuss.)

Now think through your decision. What do you want to achieve, preserve, and avoid in finding a solution. Write your answers on page 4. (Give time to write answers.)

\section{BUILDING BLOCK 4: ESTABLISH YOUR PRIORITIES (10 min.)}

In this world you don't usually get everything you want. Therefore you need to set priorities. Turn to page 5 and we'll discuss Building Block 4.

(Read through Building Block 4, giving students time to fill in answers to each section. Before they fill in section D, show them how this was done with transparencies \#3 and \#4.)

\section{BUILDING BLOCK 5: SEARCH FOR SOLUTIONS (5 min.)}

How many alternatives do you see right now that would meet your absolute requirements? Maybe there are more than you first thought.

Think about your purpose in making a decision. Think about what you want to achieve, preserve, and avoid. What ways can you think of to fulfill these? Think of all the alternatives you can, even the ones which 
seem to be improbable. Look at page 7. (Read Building Block 5, then give students time to think about possible answers.)

You are probably seeing that you lack some vital information which is needed in order to make a good decision. Now that you know what you want out of your decision situation, you also know what information you need to obtain. Since a decision can only be as good as the information upon which it is based, you owe it to yourself to go find that good information. Talk to people who are experts in appropriate areas. Brainstorm with people you trust regarding possible alternative solutions. 
LECTURE NOTES \#2

THE SEVEN BUILDING BLOCKS

\section{INTRODUCTORY REMARKS (10 min.)}

Hellol Did you think of any new and exciting alternatives for your decisions since the last session? Have you thought of some outrageous and preposterous ones?

(Hand out The Seven Building Blocks handouts to those who need them.)

Today we'll look at testing the alternatives to find which one fits best for you, but first let's review what we've learned so far. We've covered 5 Building Blocks. Can you name and explain them? (Write each Building Block on the board, and elicit explanations from the class.)

BB \#1: SMOKE OUT THE ISSUES

BB \#2: STATE YOUR PURPOSE

BB \#3: SET YOUR CRITERIA

BB \#4: ESTABLISH YOUR PRIORITIES

BB\#5: SEARCH FOR SOLUTIONS

\section{BUILDING BLOCK 6: TEST THE ALTERNATIVES (20 min.)}

Now back to the decision you were working on. Hopefully you've thought of some solutions by now, so let's consider how realistic each alternative is. Building Block 6 measures each possible solution against your priorities. Turn to page 8 in the handout and we'll see how this works.

(Explain the principles of Building Block 6 by showing and explaining transparencies \#5, \#6, and \#7. Then guide students as they fill in their alternative rating charts on page 9. Help them work through one step at a time by explaining each paragraph of section $A$ and having them do that step before explaining the next paragraph.)

Once you have filled out your chart you may immediately see a clear winner, one which you feel confident is the right solution. However, this does not always happen. Turn to page 10, and we'll look at clarifying the decision. (Read the top of page 10.) 
BULDING BLOCK 7: TROUBLESHOOT YOUR DECISION (10 $\mathrm{min}$ )

Once you have selected the alternative which you think best satisfies your criteria, and which feels to you like the right decision, you still are not quite ready to implement that decision. You still need to ask yourself the following questions:

"What if something goes wrong?"

"What could possibly go wrong?"

"What is the probability of it happening?"

"What can I do to prevent it from happening?"

"Does my decision satisfy my feelings as well as my thinking? Does it feel right?"

Building Block 7 helps you troubleshoot your decision. (Read questions on the bottom of page 10 and give students time to answer them.)

We've now worked our way through all the steps of the Seven Building Biocks. Many decision situations should be dealt with using all of these steps. But suppose that you are out for dinner and the waiter hands you a menu. You are faced with a decision, are you not? Should you get out paper and pencil and begin working your way through the entire strategy?

There are many decisions which we could call "vanilla or chocolate" decisions. They are quickly made, usually have a rather limited number of options ("Do I want vanilla ice cream or chocolate?"), and they often are not of apparent lasting significance. Yet even these decision situations can benefit from the basic principles of the Seven Building Blocks.

In any decision situation, it is appropriate to ask yourself what it is that you want to accomplish. "I want to determine the best way to..."

It is also good to decide what you want to achieve, preserve, and avoid in making a decision.

When you look at that dinner menu, what is your purpose?

What do you want to achieve, preserve, and avoid? order?

With the answers to these questions in mind, what will you then

Are there any questions or comments about Arnold's Seven Building Blocks? 
RESPONSE TO SEVEN BUILDING BLOCKS QUESTIONNAIRE (10 min.)

(Hand out the Response to Arnold's Seven Building Blocks Questionnaire.)

This is the last questionnaire in this study. Please put your ID \# at the top, then answer each question to the best of your ability.

DECISION MAKING INVENTORY RESULTS (5 min.)

(Give students their decision-making style codes. Read the information regarding decision-making styles on pages 2-4 of the "Manual for the Decision Making Inventory." Answer any questions students may have about decision-making styles.)

\section{QUESTIONS AND COIMMENTS (5 min.)}

Do you have any questions or comments regarding Arnold's Seven Building Blocks or about decision-making styles? (Answer any questions students have.)

Thank you for your cooperation in this study. I hope it has been profitable for you. Happy decision making! 
APPENDIX F

TRANSPARENCIES FOR TEACHING THE SEVEN BULDING BLOCKS 
TRANSPARENCY \#1: BUYING A WEDDING GIFT

\section{PURPOSE}

Determine the most appropriate wedding present for a friend.

\section{CRITERTA}

Achieve

A thoughtful gift, something she'll really love Something no one else is likely to give her

Something her husband will derive pleasure from

Something they can enjoy over the years

Something that will help her sew, cook, or paint

\section{Preserve}

Our friendship

Her feeling that her co-workers really care about her

Avoid

Spending more than $\$ 200$

Something that takes up a lot of space

Something that can't easily be moved 
TRANSPARENCY \#2: CHOOSING A JOB

\section{PURPOSE}

Determine the best type of work for me

\section{CRITERIA}

Achieve

$$
\text { most money }
$$

lowest mileage to work

meet interesting people

feeling of accomplishment

pleasant work atmosphere

comfortable amount of work

office privacy

freedom to work independently

good level of responsibility

appreciation and recognition of my work

learning new area of work

work for someone intelligent and understanding

normal working hours

Preserve

family responsibilities

friendships

hobbies -- golf, tennis, art

Avoid

working with "catty" people

large office

high pressure

large volume of typing

someone always on my back

menial tasks

dull work

more than 40 hour work week 
TRANSPARENCY \#3: WORKSHEET FOR CHOOSING A JOB

\section{PURPOSE}

Determine the best type of work for me

\section{CRTTERIA}

Absolute requirements

Minimum of $\$ 1500$ per month

Maximum drive to work $=10$ miles

Not leave the house before 8:00 a.m. and home by 6:00 p.m.

Desirable objectives

10 Maximum earnings

8 Freedom to work independently

$7 \quad$ Feeling of accomplishment

$5 \quad$ Time for family responsibilities

4 Pleasant work atmosphere

3 Appreciation and recognition of my work

2 Time for friends

1 Time for hobbies

1 Personal growth 
TRANSPARENCY \#4: SPENDING \$2,000

What would you do if you found you had been left $\$ 2, C$

With the decision-making skills you've learned so far, you could ask yourself the following questions:

Why is a decision necessary? (Building Block 1)

Because you've been left the money.

What needs to be determined? (Building Block 2)

The best use of the $\$ 2,000$.

What are the Criteria for making the best decisions?

(Building Block 3)

List what you want to achieve, preserve, and avoid.

What are the Priorities? (Building Block 4)

List your absolute requirements and desirable objectives.

Here's how one family listed their purpose and criteria.

\section{PURPOSE}

Determine the best use of $\$ 2,000$.

\section{CRITERIA}

Absolute requirements

Within $\$ 2,000$ limit

Not an ordinary expense

Desirable objectives

10 Something everyone in the family can enjoy

8 Something lasting

6 Something enjoyed frequently

5 Something stimulating and/or creative

4 Action preferably within three months 
TRANSPARENCY \#5: SAMPLE RATING CHART

\section{SAMPLE RATING CHART}

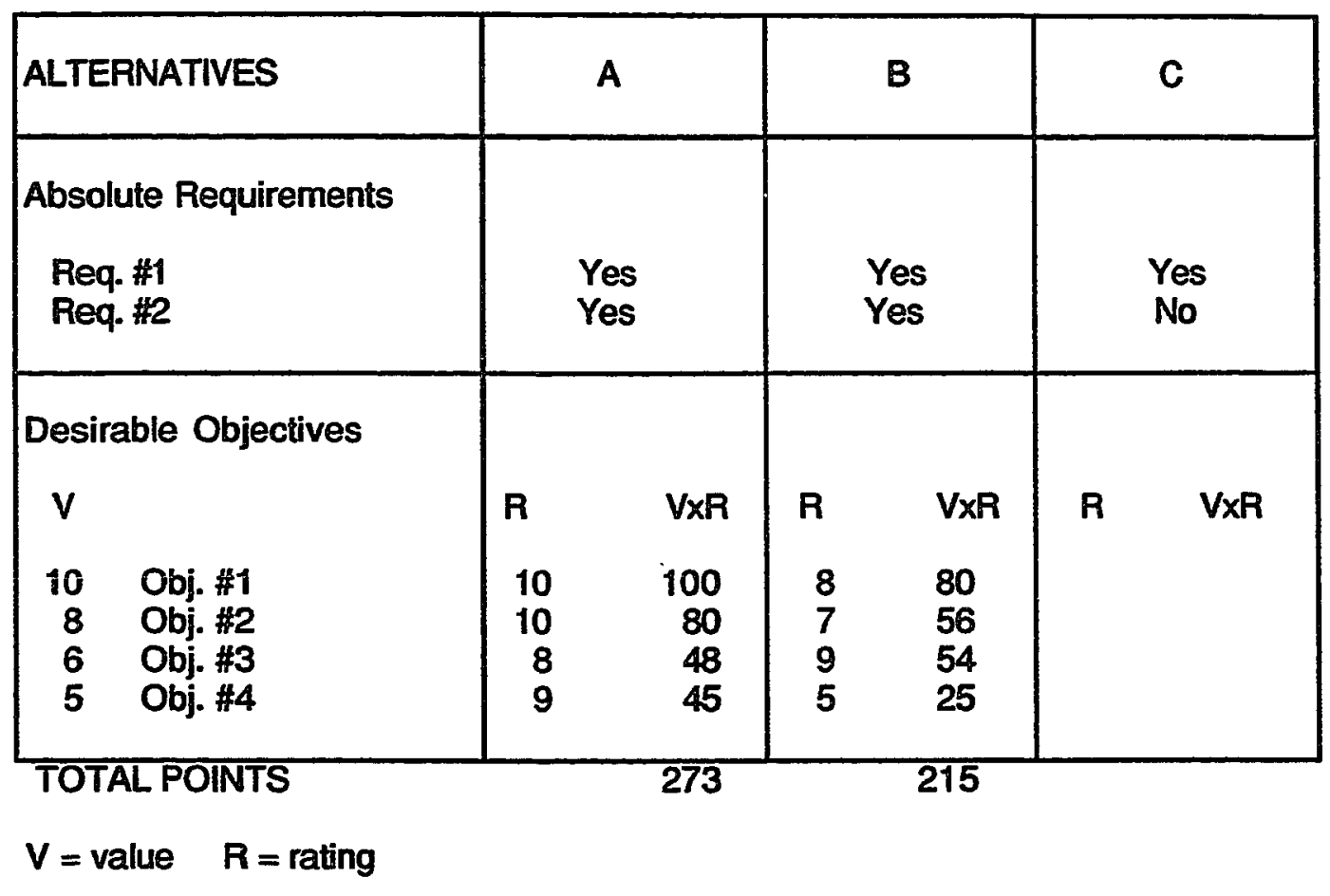


TRANSPARENCY \#6: DETERMINING THE BEST USE OF $\$ 2,000$

RATING CHART

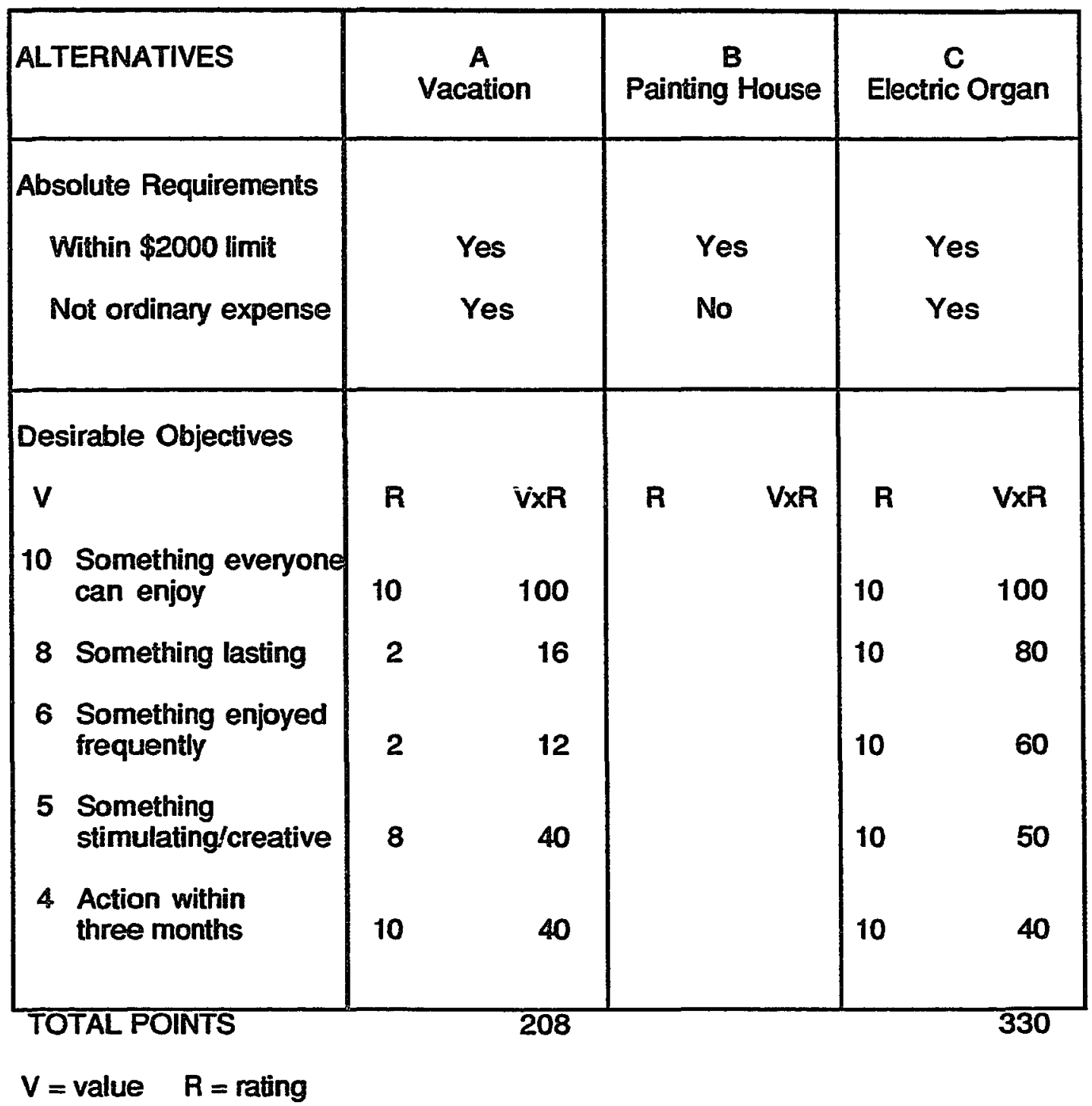


TRANSPARENCY \#7: DETERMINING THE BEST JOB

RATING CHART

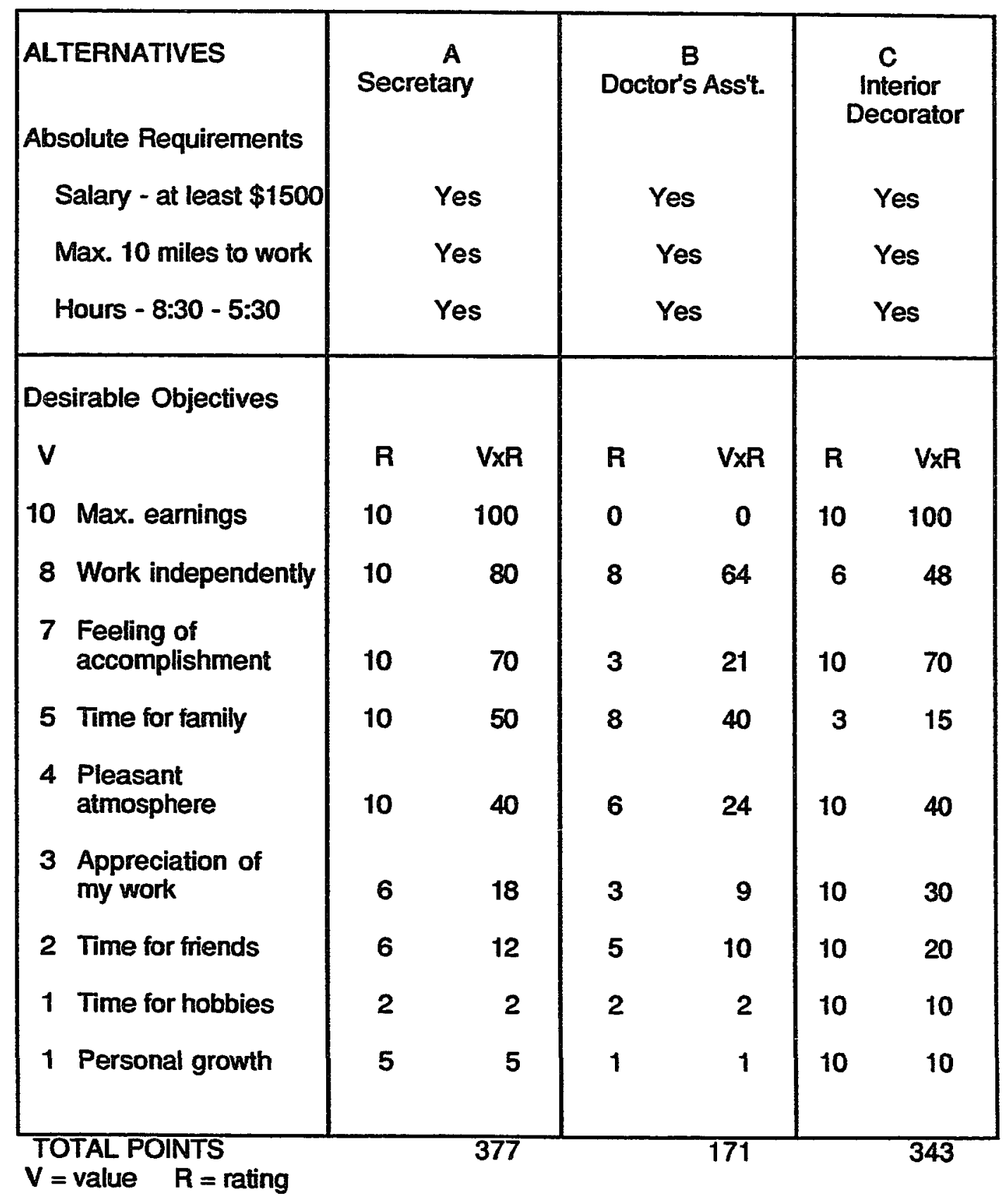


APPENDIX G

EXPLANATION OF DECISION-MAKING STYLE DIMENSIONS 
EXPLANATION OF DECISION-MAKING STYLE DIMENSIONS

Coscarelli (1983), on pages 2 through 4 of his book, Manual for the Decision Making Inventory, gives the following explanations for the various dimensions of Johnson's (1978) decision-making styles.

\section{Systematic}

Systematics move from goal to goal in a deliberate manner. They are very aware of setting goals or tasks and are not likely to deviate from the goal until it is accomplished. When faced with an alternative, the systematic will weigh all the options before choosing. Having made a choice they will stay with it for some time until more data are collected that will lead them to reconsider this choice. They think in a logical manner, and approach their decisions in an analytical way. They are cautious in choosing (though this doesn't necessarily mean slow in choosing), and having made a choice will analyze and react to it by examining the component parts before reaching a final evaluation of the event. They will tend to be more tempered in their assessment of an event--avoiding extremes.

\section{Spontaneous}

The Spontaneous (sic) will move from goal to goal easily and without deliberate thought. An established goal is easily forgotten or changed. When faced with a decision, the spontaneous will personalize the alternatives in order to evaluate them. One gets the sense they must live with an idea, however briefly, to feel what it would be like. Based on this feeling they will accept or reject an alternative. Their thought processes are thought-chaining. They will often begin a conversation on one idea and end up talking about a completely different idea. They tend to want to act on an idea and will move very quickly to a new goal or to endorse a new idea. Their reaction to events tends to be holistic and more extreme, they will either like or dislike something and evaluate it in a global sense without reference to component parts.

\section{Externality}

The external person will need to think outloud (sic). They will not be certain of a decision unless they have had the opportunity to talk about it. The more complex the decision. i.e., the more information that needs to be 
processed, the greater the need for discussion. It is not uncommon for externals to begin talking in favor of one opportunity and end up talking unfavorably of the same opportunity. This behavior should not be confused with the spontaneous characteristic of personalizing alternatives, but rather recognized as a need to hear their words in order to make sense of them. Externals will talk outloud (sic) to themselves when no one else is around to listen. These people think and talk simultaneously.

\section{Internality}

By contrast, the internal will prefer to do their (sic) processing privately before speaking. If pressed to discuss an issue they have not thought about, they will often become confused or irritated. The internal has the need for introspection before making a decision. While the externals will need to think outloud, the internals will tell you what they have already thought about. 
APPENDIX $\mathrm{H}$

STUDENT RESPONSES TO THE SEVEN BUILDING BLOCKS 


\section{STUDENT RESPONSES TO THE SEVEN BUILDING BLOCKS}

This appendix presents student responses to questions 19 and 20 from the Response to Arnold's Seven Building Blocks Questionnaire. Responses are given precisely as students wrote them, including spelling, punctuation, and underlining. Each student's responses to the two questions are listed together. The comments set apart by the first set of quotation marks are the response to question 19, and those in the second set are the response to question 20. The comments of high school students will be listed first, followed by those of college students. Comments are grouped by decision-making style. The age of each student is given with the comments, as is each student's attitude score.

Questions 19 and 20 read as follows:

19. Describe briefly your reactions to Arnold's Seven Building Blocks.

20. What changes would you like to see made in the Seven Building Blocks? Describe them briefly.

\section{COMMENTS OF HIGH SCHOOL STUDENTS}

DECISION-MAKING STYLE: SPONTANEOUS INTERNAL AGE: 16 ATTITUDE SCORE: LOW

"I think it is helpful in fully analysing a decision making process, but I do not feel that it is fully necessary."

"I don't think that a person needs to rate their decisions in a scale, to me that's pointless, it just takes to much time. All this can be done in the head, in a matter of seconds. A wise decision does not require all these steps."

DECISION-MAKING STYLE: SPONTANEOUS INTERNAL AGE: 17 ATTITUDE SCORE: LOW

"I thought that it was way too drawn out \& boring."

"I don't care as long as I don't use it anymore."

DECISION-MAKING STYLE: SPONTANEOUS INTERNAL AGE: 17 ATTITUDE SCORE: MEDIUM

"It really broke down the process. Took too long on things that were useless to me."

"\#1 is not necessery \#5 really does not offer anything helpful" 
DECISION-MAKING STYLE: SPONTANEOUS INTERNAL AGE: 16 ATTITUDE SCORE: LOW

"I feel it is not good for making all decisions and it is not good for all people to use."

"It does not really concern me so Im not worried about them."

DECISION-MAKING STYLE: SPONTANEOUS EXTERNAL AGE: 18 ATTITUDE SCORE: HIGH

"It was good. It made me think through my decision. I felt more confident on my choice."

"take more time to see if the alternative you choose will really make you happy."

DECISION-MAKING STYLE: SPONTANEOUS EXTERNAL AGE: 18 ATTITUDE SCORE: LOW

"It was to long to make a decision. They put to much stress on a person"

"I don't know"

DECISION-MAKING STYLE: SPONTANEOUS EXTERNAL AGE: 17 ATTITUDE SCORE: HIGH

"I think that I could use this as a tool to help decide many things in my future life."

"I like it just the way it is."

DECISION-MAKING STYLE: SPONTANEOUS EXTERNAL AGE: 18 ATTITUDE SCORE: LOW

"It may be a good idea but decision I choose to use was one where I was already in the troble shooting stage this is where my difficulty was in making a decision."

"I would like to see this process simpified a little less repotian \& stating of the ovious."

DECISION-MAKING STYLE: SPONTANEOUS EXTERNAL AGE: 18 ATTITUDE SCORE: MEDIUM

"They take too long, but they are very thorough. For a large decision they would be helpful."

"Make it shorter."

DECISION-MAKING STYLE: SPONTANEOUS EXTERNAL AGE: 18 ATTITUDE SCORE: LOW

"I thought it was to analitical and may work great for some people, but for me I use my feelings more than charts and numbers. I think people try to look towards scientific things to oftend and forget what life is all about. This might apply better to large groups and not individuals." 
DECISION-MAKING STYLE: SYSTEMATIC INTERNAL

AGE: 18 ATTITUDE SCORE: MEDIUM

"It wasn't so bad. Worked allright for me."

"The Blocks are probably fine for most people and didn't really need any changes, maybe a shorter booklet"

DECISION-MAKING STYLE: SYSTEMATIC INTERNAL ATTITUDE SCORE: MEDIUM

AGE: 18

"I didn't think all the steps were necessary the first few were good"

"It needs to be shorter and its a little repetitious"

DECISION-MAKING STYLE: SYSTEMATIC INTERNAL

AGE: 17

ATTITUDE SCORE: MEDIUM

"My reaction was okay. I feel that Arnolds Seven Building Blocks is a subject just be discussed more."

"Just that you need more time in going through it."

DECISION-MAKING STYLE: SYSTEMATIC INTERINAI ATTTUDE SCORE: MEDIUM

"Interesting"

AGE: 16

DECISION-MAKING STYLE: SYSTEMATIC INTERNAL

AGE: 18 ATTITUDE SCORE: MEDIUM

"This is a good way to make bisness decisions but I do not feel it is right for me"

DECISION-MAKING STYLE: SYSTEMATIC INTERNAL

AGE: 16 ATTITUDE SCORE: LOW

"I thought it took to long, and was too much useless writing."

"Many less steps."

DECISION-MAKING STYLE: SYSTEMATIC EXTERNAL ATTITUE SCORE: LOW

AGE: 16

"I thought it analyzed the problem too much and a couple of steps weren't neccessary."

"Too many steps to arrive at a decision."

DECISION-MAKING STYLE: SYSTEMATIC EXTERNAL ATTITUDE SCORE: MEDIUM

"analyze too much. A lot of us don't have MAJOR decisions to make. And if they can't make up their minds, the f...."

"can't explain when i don't understand fully. We were told to come up w/ a major decision. I don't have any major decisions 2 make. I had to make one up. nothing is bugging me now." 
DECISION-MAKING STYLE: SYSTEMATIC EXTERNAL

AGE: 17 ATTITUDE SCORE: MEDIUM

"It was way too much to go through just to make a decision. A person doesn't usually have to go through all of that just to reach a decision. Most of us make up our minds very quickly and easily."

"Shorten them to 5 or so building blocks. Some of the building blocks were useless."

DECISION-MAKING STYLE: SYSTEMATIC EXTERNAL AGE: 18 ATTITUDE SCORE: MEDIUM

"It seemed to long to make a simple dicision. It was somewhat confussing also."

"It seem a quicker method could be made."

DECISION-MAKING STYLE: SYSTEMATIC EXTERNAL AGE: 17 ATTITUDE SCORE: LOW

"Some parts made sense, some parts seemed unneccessary, some you totally lost me on."

"make the search for solutions and \#6 easier to understand."

DECISION-MAKING STYLE: SYSTEMATIC EXTERNAL AGE: 18 ATTITUDE SCORE: LOW

"Too long for a decision that you just have to think about, but it looked helpful in some difficult decision making situtations."

"Make it shorter!"

DECISION-MAKING STYLE: SYSTEMATIC EXTERNAL AGE: 17 ATTITUDE SCORE: HIGH

"They are helpful."

"none"

DECISION-MAKING STYLE: SYSTEMATIC EXTERNAL ATTITUDE SCORE: HIGH

AGE: 18

"I think that Arnold's Seven Building Block is very helpful and certain parts are more helpful than other"

"I don't really know."

DECISION-MAKING STYLE: SYSTEMATIC EXTERNAL

AGE: 17 ATTITUDE SCORE: MEDIUM

"It was helpful but I think there are easy ways to make a decision." "Shorten it down" 
DECISION-MAKING STYLE: SYSTEMATIC EXTERNAL

AGE: 17 ATTITUDE SCORE: MEDIUM

"Well planned. It cover all major important steps in making a decision"

"If one actually sits down and fills out every single blank line, it becomes to long of a process for simpler decision. Building block two is not necessary."

DECISION-MAKING STYLE: SYSTEMATIC EXTERNAL AGE: 17 ATTITUDE SCORE: MEDIUM

"They were very dry. I almost fell asleep. They would probably work but I think there are faster, more effective ways to work it out. These put too much stress on a person."

"Make them shorter and not so involved. Easier to understand, not so monotonous."

DECISION-MAKING STYLE: SYSTEMATIC EXTERNAL $\quad$ AGE: 18 ATTITUDE SCORE: MEDIUM

"The process has its advantages but it is an unemotional way to make a decision. I simply could not make a decision using those seven Building Blocks. Its too impersonal."

"They should be more relaxed about issues."

DECISION-MAKING STYLE: SYSTEMATIC EXTERNAL AGE: 17 ATTITUDE SCORE: MEDIUM

"I think that it is a good system. It is helpful in making major decisions." 
COMMENTS OF COLLEGE STUDENTS

DECISION-MAKING STYLE: SPONTANEOUS INTERNAL AGE: 23 ATTITUDE SCORE: MEDIUM

"I don't quite understand everything because I missed Tuesday because I work. I feel those technics will assist in making my decisions though."

DECISION-MAKING STYLE: SPONTANEOUS INTERNAL AGE: 22 ATTITUDE SCORE: LOW

"I feel that it is a good method for a non-Christian, but it doesn't take into consideration the working of the Holy Spirit \& God. I feel that prayer is an important factor and seeking God's will for my life. I also know that I might not always feel right about the decision I made yet if I know that God is in control and has a plan for my life I am able to step out in faith and trust God to guide \& direct me."

"Well if your teaching it in a secular environment I feel that it is pretty well organized and will work for people. But in a Christian environment you need to allow for God to interact in your decision making process. And I also would include the advice and opinions of others within the process."

DECISION-MAKING STYLE: SPONTANEOUS EXTERNAL AGE: 22 ATTITUDE SCORE: LOW

"I did not enjoy the analytical side of it. I tended to be an emotional decision maker who makes decisions on the spur of the moment. It was hard for me to sit and assign numbers to the criteria. But I think that overall, it is much better for me to use this method sometime. It's like taking medicine. You know it's suppose to help you, but you don't like it anyway."

"Too much writing. Too many steps to go through."

DECISION-MAKING STYLE: SPONTANEOUS EXTERNAL AGE: 21 ATTITUDE SCORE: MEDIUM

"I feel like my problem didn't end up being a good one for this because we already made a decision based on other things before I was finished. I did come up with the same decision though."

DECISION-MAKING STYLE: SPONTANEOUS EXTERNAL AGE: 22 ATTITUDE SCORE: MEDIUM

"It takes timel (obviously) It was (is) difficult to know how well it actually might work for my dicision because I have much more to think about than what I had time today." 
DECISION-MAKING STYLE: SYSTEMATIC INTERNAL

AGE: 20 ATTITUDE SCORE: MEDIUM

"good decision making strategy, perhaps too complicated and demanding for decisions of not so high importance"

"perhaps modify the steps to reduce the \# of steps needed to complete the exercise"

DECISION-MAKING STYLE: SYSTEMATIC INTERNAL

AGE: 19 ATTITUDE SCORE: MEDIUM

"It helped me somewhat"

"Not sure yetIl!"

DECISION-MAKING STYLE: SYSTEMATIC INTERNAL

AGE: 20

ATTITUDE SCORE: MEDIUM

"Very useful tool -- helps you look at problems and decisions from all sides"

"I feel in no position to be judgemental"

DECISION-MAKING STYLE: SYSTEMATIC INTERNAL ATTITUDE SCORE: HIGH

"Determining one's values is (well, for me anyway) a terribly inexact science. It seems the decision is either clear (forget the math, then) or it is too close to call. However, for decisions oriented towards tasks or jobs that were more complex the technique as presented would be excellent."

'The 'state your problem' seems rather redundent. Another reaction I have to [it] is an answer looking for a problem."

DECISION-MAKING STYLE: SYSTEMATIC INTERNAL

AGE: 20 ATTITUDE SCORE: MEDIUM

"Very thorough but maybe to much."

"I would value trouble shooting more."

DECISION-MAKING STYLE: SYSTEMATIC INTERNAL

AGE: 20 ATTITUDE SCORE: LOW

"I understand the principles behind them. I can see how they would be helpful. However I personally find them to be tedious and not a great deal of help."

"I can't think of anything to improve them. I'm sure they work but I don't like them."

DECISION-MAKING STYLE: SYSTEMATIC INTERNAL ATTTTUDE SCORE: MEDIUM

AGE: 20

"I felt it lacked an aid to creative thinking -- in generating solutions it would have been helpful to have suggestions as to what to think about $\&$ how to come up with 'new' ideas." 
DECISION-MAKING STYLE: SYSTEMATIC INTERNAL

AGE: 23 ATTITUDE SCORE: HIGH

"It was very interesting and helpful -- helped me to pinpoint the areas that were of great importance to me and left me knowing what exact areas needed to be researched."

"use of more examples on overhead"

DECISION-MAKING STYLE: SYSTEMATIC INTERNAL

AGE: 21 ATTITUDE SCORE: MEDIUM

"Very interesting -- I was already making a decision that I have been thinking about prior this questionnaire. This questionnaire came on a very good time and the very first parts 1-4 put my problem and solutions into perspective."

"No change"

DECISION-MAKING STYLE: SYSTEMATIC INTERNAL

AGE: 20 ATTITUDE SCORE: HIGH

"I am excited about taking more time to work through some decisions taking more time and asking God for guidance using this structure." "None that I can think of yet."

DECISION-MAKING STYLE: SYSTEMATIC INTERNAL

AGE: 20 ATTITUDE SCORE: HIGH

"it is a thorough approach to decision making. It was well worth my time and will help me make decisions that I will feel better about."

DECISION-MAKING STYLE: SYSTEMATIC INTERNAL ATTTTUDE SCORE: HIGH

"It gives me a good systematic way to make decisions. I sometimes put off making a decision because I don't know where to start. With the Arnold's Seven Building Blocks, I now have the steps to get me started toward a good sol'n."

"I think they are great just the way they are presented now."

DECISION-MAKING STYLE: SYSTEMATIC INTERNAL ATTITUDE SCORE: HIGH

AGE: 23

"It seems to be a powerful tool to help think thru the possible options $\&$ reach the best decision. I am pleased \& feel confident that I can use this in future decisions."

"Smoke out the issues seemed like going back beyond the starting point, since I had been mulling over this decision for quite some time \& have a good handle on the problem itself." 
DECISION-MAKING STYLE: SYSTEMATIC INTERNAL

AGE: 19 ATTITUDE SCORE: MEDIUM

"It helped me somewhat"

"Not sure yetII!"

DECISION-MAKING STYLE: SYSTEMATIC INTERNAL

AGE: 20 ATTITUDE SCORE: MEDIUM

"good decision making strategy, perhaps too complicated and demanding for decisions of not so high importance."

"perhaps modify the steps to reduce the \# of steps needed to complete the exercise."

DECISION-MAKING STYLE: SYSTEMATIC EXTERNAL

AGE: 19 ATTITUDE SCORE: MEDIUM

"rating to vague"

"more attention to breaking down criteria"

DECISION-MAKING STYLE: SYSTEMATIC EXTERNAL ATTITUDE SCORE: MEDIUM

AGE: 19

"I think it's good to know of a technique on making decisions that are difficult to make off hand. It shows what I value and how the choices rate."

"Be specific on what kinds of decisions can be used with this technique."

DECISION-MAKING STYLE: SYSTEMATIC EXTERNAL ATTITUDE SCORE: MEDIUM

"I liked them-- a little complex for some decisions, but it's a good system for the big, important issues."

DECISION-MAKING STYLE: SYSTEMATIC EXTERNAL

AGE: 19 ATTITUDE SCORE: MEDIUM

"It started out to be very interesting, but my thinking was at a stand still and I kept going round and round as I was trying to think. I didn't get to finish and that was really frustrating to me. I don't think my evaluation can thoroughly help you."

"I don't know."

DECISION-MAKING STYLE: SYSTEMATIC EXTERNAL ATTITUDE SCORE: MEDIUM

AGE: 19

"Was helpful because it asks the questions I should be asking myself-but I don't."

"none" 
DECISION-MAKING STYLE: SYSTEMATIC EXTERNAL

AGE: 21 ATTITUDE SCORE: HIGH

"The strategy is a very time consuming one. But I feel that for important decisions we need to make it is worth taking the time to sort out priorities, come up w/ alternatives and make the appropriate decision. I also find it to be a decision making strategy that is very personal. What I mean is that you will only get out of it what you as a person are capable of putting into it. It depends on who you are as a person. What your morals are. If affects you as a person, disregarding the environment around you. Unless you are a person who takes others into consideration."

DECISION-MAKING STYLE: SYSTEMATIC EXTERNAL

AGE: 21 ATTITUDE SCORE: MEDIUM

"In being a process, it makes one sit down and really think through all the questions raised in this process, perhaps some not thought of on your own. It also helps to show options maybe not considered before as fitting the scheme of prioritys."

"Maybe a little explanation written about step 3 as to what each of those means -- what sort of things are being asked for."

DECISION-MAKING STYLE: SYSTEMATIC EXTERNAL

AGE: 20 ATTITUDE SCORE: HIGH

"I wouldn't us it all the way thru on all decisions-- only on very difficult decisions might I use it all. I liked the way it broke down the problems of decision making into clear cut 'blocks.' It helped me especially in areas I have problems seeing/understanding clearly."

"Clarify that the alternatives are the best of the combined or single solutions from the Block 5. My solutions were too detailed \& I had to generalize a great deal to have alternatives for \#6. Perhaps it could be said in the instructions of \#5 that you need to choose the best possible solutions out of those you listed \& then list those as alternatives in the chart."

DECISION-MAKING STYLE: SYSTEMATIC EXTERNAL

AGE: 20 ATTITDE SCORE: HIGH

"3.4.7 are the major one's I would include, but. I felt that the whole process was good. Not only does a person go through thought of what the questions ask, but they must write down their answer. Writing is a super way to make a decision. I think it's a really good system. The only draw back is that it is time consuming, but if a decision is important enough, you'll take the time."

"The absolute req. meeting the alternatives is a little hazy."

DECISION-MAKING STYLE: SYSTEMATIC EXTERNAL AGE: 21 ATTITUDE SCORE: HIGH

"This is not a radical approach to decision making and can easily be applied to many decisions. It was most helpful in determining 
priorities. I think my gut would still probably speak louder than the tally points."

"Why on 6. Testing the alternatives do you rate the alternatives on a scale from 1 to 10 rather than on the number of alternatives ie. with 3 alternatives, the best gets 3 , and the worst gets 2 . Ties are ties."

DECISION-MAKING STYLE: SYSTEMATIC EXTERNAL ATTITUDE SCORE: HIGH

AGE: 20

"It helped me look at a few alternatives that I had previously ruled out, and to give them a fair shake. It made me think about where my priorities are. Its a thought provoking guideline thats useful."

"I think its fine as a guideline. Its a little to complex for minor decisions and a little to simple for major decisions but it makes a good guideline for all decisions."

DECISION-MAKING STYLE: SYSTEMATIC EXTERNAL ATTITUDE SCORE: HIGH

AGE: 19

"I thout these Seven Building Blocks were very helpful in my decision. It made it clear what I should do, and why I should do it. It also helps me to rely more on myself for making decisions, and not as much on other people."

"I can't think of anything right now that I would like to see changed. All of the steps helped me, and they were presented well."

DECISION-MAKING STYLE: SYSTEMATIC EXTERNAL ATTITUDE SCORE: LOW

AGE: 20

"I think it would work better if I had all the time it takes to go through this. I guess I just get frustrated sitting here writing out everything. It works better for me to think \& talk things through." "I think it takes a certain type of person to sit down and write out their thoughts \& feelings on an issue, and this strategy would work for some. But for me, I would shorten the strategy so it didn't take so much time, because I just can't see myself having the time to sit and work through it."

DECISION-MAKING STYLE: SYSTEMATIC EXTERNAL ATTITUDE SCORE: HIGH

AGE: 22

"I like it. I think it is rather detailed for very common decisions, but certainly very useful for life-affecting decisions. One question I have is how do outside influences (God, friends) become part of my decision: that is. I feel that I should also pray and talk this over w/ others. Can this be done w/ friends? -- They may think of things that I would forget."

"Allow this to be spread out over time so that I don't have to repeat it if I find some lacking information." 
DECISION-MAKING STYLE: SYSTEMATIC EXTERNAL ATTITUDE SCORE: MEDIUM

"It is long, involving and takes a lot of thought, but more structured and hence, more organized than stewing or stretting (sic) over the decision. For some I almost think my 'final' decision would still not be final -- but then I didn't complete the full process with adequate time."

"It allows only a little of consultation with others. Perhaps that's not aiways available, but to consider the opinion of informed souirces representing each alternative would make the system less dependent on your biased decision and a numerical formula."

DECISION-MAKING STYLE: SYSTEMATIC EXTERNAL

AGE: 19 ATTITUDE SCORE: MEDIUM

"rating to vague"

"more attention to breaking down criteria" 